ANUARIO DE Estudios MEDIEVALES (AEM)

36/1, enero junio de 2006

pp. 295-333

ISSN 0066-5061

\title{
¿NEGOCIAR LA ENTRADA DEL REY? LA ENTRADA REAL DE JUAN II EN BARCELONA (1458)
}

\author{
Miguel Raufast CHICO \\ Institución Milá y Fontanals \\ CSIC, Barcelona
}

\begin{abstract}
Resumen: Basado en documentación archivística generada por la entrada real de Juan II como nuevo monarca de la Corona de Aragón en Barcelona en 1458, este artículo llama la atención sobre el proceso de preparación de este tipo de ceremonias, en el cual intervienen tanto el rey como la ciudad. Al mismo tiempo, se intenta mostrar que el diálogo que se establece entre ambas partes en relación a este hecho puede llegar, en determinadas circunstancias, a asimilarse a una negociación.
\end{abstract}

Palabras clave: Entrada real;Ceremonia de recepción urbana; Negociación; Juan II; Barcelona; Siglo XV.

\begin{abstract}
Based on the archival documents generated by John II's royal entry to Barcelona as the new king of Aragon in 1458, this article explores the process involved in preparing for this ceremonies. It also aims to show that in certain circumstances the dialogue between king and city - the two parties concerned- that led to the final conception of this elaborate ceremony, might almost be considered a kind of negotiation.
\end{abstract}

Keywords: Royal entry; Urban welcome ceremony; Negotiation; John II; Barcelona; 15 th Century.

\section{SUMARIO}

1. Introducción.- 2. Esperando al nuevo rey.- 3. Preámbulos.- 4. ¿Negociación?- 5. Epílogo. Mapas. Apéndice documental. 


\section{INTRODUCCIÓN ${ }^{1}$}

Aunque no puede afirmarse que la entrada real bajomedieval carezca, en términos generales, de una cierta tradición historiográfica ${ }^{2}$, la realidad es

${ }^{1}$ Este trabajo se inscribe en el marco del Proyecto de Investigación aprobado y financiado por la DGCYT: "Entre la Península Ibérica y el Mediterráneo. Interacciones políticas, económicas y culturales de la Corona de Aragón en la Baja Edad Media" (HUM2004-000916), dirigido por la Dra. Roser Salicrú i Lluch.

Quiero agradecer la valiosa colaboración de Esther Redondo en el diseño de los mapas que acompañan este artículo. Para los mapas 2, 3 y 4 se ha utilizado como base gráfica el trabajo de Alberto GARCÍA ESPUCHE y Manuel GUÅRDIA BASSOLS, Espai $i$ societat a la Barcelona preindustrial, Barcelona, 1986, fig. 9

Abreviaturas utilizadas: $\mathrm{ACA}=$ Archivo de la Corona de Aragón; $\mathrm{AHCB}=$ Archivo Histórico de la Ciudad de Barcelona; AHCTE=Archivo Histórico Comarcal de las Tierras del Ebro; $\mathrm{AML}=$ Archivo Municipal de Lérida; $\mathrm{C}=$ Cancillería; $\mathrm{CC}=$ Consell de Cent; CODOIN = Colección de Documentos Inéditos del Archivo de la Corona de Aragón; f., ff. = folio, folios; reg. = registro; r. = recto; v. = verso.

${ }^{2}$ Obras seminales como las de Bernard Guenée y Françoise LAHOUX, Les entrées royales françaises de 1328 a 1515, París, 1968; Jacques HEERs, Fêtes, jeux et joutes dans les sociétés d'Occident à la fin du Moyen Âge, París, 1971; o Elie KonIGSON, L'espace théâtral médiéval, París, 1975, crearon, en su momento, modelos clásicos para el mundo francófono que, con el tiempo, se han visto modificados o matizados por nuevos estudios de carácter más local, entre los cuales pueden destacarse las contribuciones de Lawrence M. BRYANT, La cérémonie de l'entrée à Paris au Moyen Age, "Annales", 3 (1986), pp. 513-542; Nadia Mosselmans, Les villes face au prince: $l^{\prime}$ importance réelle de la cérémonie d'entrée solennelle sous le règne de Philippe le Bon, en Jean-Marie DUSVOSQUEL; Alain DIERKENS (coords.), Villes et campagnes au Moyen Âge (Mélanges Georges Despy), Lieja, 1991, pp. 537-548; Noël COULET, Les entrées solennelles en Provence au XIVe siècle, "Ethnologie Française", 7/1 (1997), pp. 63- 82; o David RIVAUD, Les entrées royales dans les "bonnes villes" du Centre-Ouest aux XVe et XVI siècles: théâtres et décors historiés, en Noël COULET; Olivier GUYOTJEANNIN (dirs.), La ville au Moyen Âge (vol. II: Société et pouvoirs dans la ville), París, 1998, pp. 277-294. Igualmente, junto a aquellos trabajos que mejor ejemplifican la aproximación al tema desde el estudio de los ritos de la realeza, como podrían ser los de Sergio BERTELLI, The King's Body, Pennsylvania, 2001 (edición original en italiano en 1990); o de Gordon KIPLING, Enter the King. Theatre, Liturgy and Ritual in the Medieval Civic Triumph, Oxford, 1998, es posible encontrar aportaciones en las que, aún de una manera un tanto tímida, se intenta resaltar el protagonismo del ceremonial institucional urbano, como las de Brigitte BEDOS-REZAK, Civic Liturgies and Urban Records in Northern France, 1100-1400, pp. 34-55; y Lorraine ATTREED, The Politcs of Welcome. Ceremonies and Constitutional Development in Later Medieval English Towns, pp. 208-231, ambas en Barbara HANAWALT; Kathryn L. REYERSON (eds.), City and Spectacle in Medieval Europe, Minneapolis, 1994. Por lo que respecta a los territorios de la Península Ibérica, la producción sigue siendo deficitaria. Para el reino de Castilla, pueden destacarse, casi únicamente, las contribuciones de Rosana de ANDRÉS, Las "entradas reales castellanas" en los siglos XIV y XV, según las crónicas de la época, "En la España Medieval", 4 (1984), pp. 47-62; Antonio del Rocío ROMERO ABAO, Las fiestas de Sevilla en el siglo XV, Madrid, 1991; José Manuel NIETO SORIA, Ceremonias de la realeza. Propaganda y legitimación en la Castilla Trastámara, Madrid, 1993; o Ana Isabel CARRASCO, Discurso político y propaganda en la corte de los Reyes Católicos: resultados de una primera investigación (1477-1482), "En la España Medieval", 25 (2002), pp. 299-379. En cuanto al reino de Valencia, la entrada real quizá sí haya sido abordada con una mayor insistencia, aunque los estudios sobre ella se centren exclusivamente en una única ciudad: Salvador CARRERES ZACARÉS, Ensayo de una bibliografía de libros de fiestas celebradas en Valencia y su antiguo reino, Valencia, 1925; Joan OLEZA, Las transformaciones del fasto medieval, en Luis QUIRANTE, Teatro y espectáculo en la Edad Media, Elche, 1992, pp. 47-64; Rafael NARBONA, Las fiestas 
que la complejidad inherente a este tipo de ceremonias ha dificultado enormemente la posibilidad de ofrecer una imagen exacta de su verdadera dimensión. Prueba de ello es que, a pesar de las numerosas y variadas definiciones que han sido sugeridas en relación a dichos eventos - "contrato feudal", "acto de sumisión", "ceremonia de inauguración" o "contrato social", por citar tan sólo algunos ejemplos-, ninguna de ellas, sin dejar de ser esencialmente cierta, resulta satisfactoria por entero, incapaz de integrar conceptualmente los múltiples elementos que confluyen en la escenificación de la entrada solemne del monarca en las ciudades de finales de la Edad Media ${ }^{3}$.

Sin perder de vista, por supuesto, los matices cronológicos y geográficos que sitúan a toda celebración en su exacto contexto histórico ${ }^{4}$, nos

reales en Valencia entre la Edad Media y la Edad Moderna (siglos XIV-XVII), "Pedralbes", 13 (1993), pp. 463-472; IDEM, Cortejos ceremoniales, funciones religiosas y simbolismos políticos en las ciudades medievales, en Teatro medieval, teatro vivo, Elche, 2001, pp. 119-134; IDEM, Memorias de la ciudad. Ceremonias, creencias y costumbres en la historia de Valencia, Valencia, 2003; Teresa FERRER VALLS, La fiesta cívica en la ciudad de Valencia en el siglo XV, en Evangelina RoDRíGUEZ (ed.), Cultura y representación en la Edad Media, Valencia, 1994, pp. 145-169; Vicente ADELANTADO, Una consueta del siglo XV, "Lemir: Revista Electrónica sobre Literatura Española Medieval y Renacimiento", 8 (2004) (http://parnaseo.uv.es/Lemir /Revista/Revista8/Adelantado.htm). Finalmente, por lo que se refiere a Cataluña, el panorama resulta desolador, y apenas es posible mencionar un par de artículos: Francina SOLSONA, Entrada del futur Ferran el Catòlic a Cervera (1461), "Estudios Históricos y Documentos de los Archivos de Protocolos", VII (1979), pp. 163-167; Ramon MIRÓ I BALDRICH, Fasts reials a Tàrrega a finals de l'Edat Mitjana, "Urtx", 5 (1993), pp. 131-148, a los cuales ciertamente habría que añadir el trabajo que Francesc Massip ha venido desarrollando, a lo largo de estos últimos años, sobre los aspectos propagandísticos del ceremonial monárquico en la Cataluña bajomedieval y moderna (véanse, especialmente, Francesc MASSIP, El rei i la festa. Del ritu a la propaganda, "Revista de Catalunya", 84 (1994), pp. 17-37; IDEM, La monarquía en escena, Madrid, 2003).

${ }^{3}$ El calificativo de "hecho social total", concebido inicialmente por el sociólogo Marcel Mauss en relación a aquellos fenómenos de análisis poliédrico que incorporaban al mismo tiempo elementos jurídicos, estéticos, económicos o religiosos (Sociologie et Anthropologie, París, 1968, p. 274), y aplicado posteriormente por Elie Konigson a la entrada real medieval (L'espace théâtral, p. 254), continúa siendo válido -a pesar de que para la antropología actual todo "hecho social" sea "total"- para expresar los muy diversos enfoques desde los cuales puede abordarse el estudio de esta ceremonia.

${ }^{4}$ En realidad, el estudio de la entrada real medieval no dispone aún de ninguna obra de conjunto que haya investigado su historia y evolución en el tiempo. En este sentido, la apreciación de Christian de Mérindol en relación al mundo francés resulta ilustrativa y perfectamente extrapolable a la Europa medieval: «Entre l'entrée du roi Gontran dans Orléans le 2 juin 588 et les entrées du XIV ${ }^{\mathrm{e}}$ siècle, un grand vide qu'il faudrait combler» (Christian de MÉRINDOL, Théâtre et politique à la fin du Moyen Âge. Les entrées royales et autres cérémonies. Mises au point et nouveaux aperçus, en Théâtre et spectacles hier et aujourd'hui. Moyen Âge et Renaissance, "Actes du 115 ${ }^{\mathrm{e}}$ Congrès National des Sociétés Savantes" (Aviñón, 1990), París, 1991 , p. 180, nota 5). Se han de reseñar, en cualquier caso, las aportaciones de Ernest H. KANTOROWICZ, The "King's Advent" and the Enigmatic Panels in the Doors of Santa Sabina, "Art Bulletin", 26:4 (1944), pp. 207-231; IDEM, Laudes regiae. A Study in Liturgical Acclamations and Mediaeval Ruler Worship, Berkeley, 1958, sobre la influencia del adventus bíblico (la entrada de Jesús en Jerusalén) en la entrada real medieval; y de Michael MCCORMICK, 
gustaría aquí llamar la atención sobre dos aspectos, uno teórico y otro de carácter metodológico, que probablemente no han sido objeto de suficiente reflexión a la hora de estudiar la entrada real y que contribuyen, a nuestro juicio, a distorsionar tanto la comprensión como la interpretación del fenómeno.

Es posible que el concepto de "ceremonia real"5, ampliamente aceptado en relación a la entrada real, se haya convertido, a la larga, en un lastre para la investigación sobre dicho tema. Aun cuando determinados autores ya han reparado en la importancia del papel que juegan las ciudades en la materialización de estos eventos ${ }^{6}$, ello no ha impedido que, prioritariamente, en el momento de plasmar el encuentro entre soberano y urbe, continúe prevaleciendo, por encima de cualquier otra circunstancia, la imagen protagonista del rey, destacada sobre un escenario - activo o pasivo- que sólo parece tener razón de ser en la medida en que se adecúa a las necesidades ceremoniales de la monarquía.

Frente a ello, la consulta - siempre que esto es posible- de las fuentes archivísticas municipales tiende a poner invariablemente de manifiesto cómo la ciudad, al igual que el monarca, construye su propia ritualidad ceremonial, y cómo ésta, además, es utilizada de manera institucional, tanto en aquellos actos que cohesionan internamente al municipio - por ejemplo, las procesiones-, como en aquellos otros que lo reivindican externamente -embajadas o representaciones en Cortes ${ }^{7}$. La entrada real, que, desde el

Eternal victory. Triumphal Rulership in Late Antiquity, Byzantium, and the Early Medieval West, Cambridge, 1986, acerca de la decisiva herencia dejada por el triumphus romano en las ceremonias de entrada medievales.

${ }^{5}$ Concepto especialmente potenciado por los representantes de la bautizada, desde Francia, como école ceremonialiste américaine. Para estos autores -utilizando las palabras de Fanny Cosandey-, «est finalment cérémonie royale tout ce qui touche à la mise en scène du roi ou de la reine, quelle que soit la nature de l'événement» (Fanny COSANDEY, La reine de France. Symbole et pouvoir. XV $V^{e}$-XVIII siècle, París, 2000, p. 124). Cosandey se refiere, entre otros, a Ralph E. GIESEY, Cérémonial et puissance souveraine. France, XV $-X V I I^{e}$ siècles, París, 1987; y a Lawrence M. BRYANT, The King and the City in the Parisian Royal Entry Ceremony, Ginebra, 1986.

${ }^{6}$ A los nombres de Brigitte Bedos-Rezak, Lorraine Attreed, Joan Oleza o Antonio del Rocío Romero Abao, ya citados en la nota 2, pueden añadirse, entre otros, los de Anne-Marie LECOQ, $\mathrm{La}$ "Città festeggiante". Les fêtes publiques au XV et XVI siècles, "La Revue de l'Art", 33 (1976), pp. 83-100; o el propio Lawrence M. BRYANT, Configurations of the Community in Late Medieval Spectacles: Paris and London During the Dual Monarchy, en B. HANAWALT, City and Spectacle, pp. 3-31.

${ }^{7}$ Para el caso que nos ocupa, como es el de la ciudad de Barcelona, las Rúbriques de Bruniquer constituyen un magnífico testimonio tanto de la ritualidad que gobierna, en todo momento, la actuación de los regidores municipales, como del cuidado formal con el que se 
punto de vista urbano, podría considerarse como la suma dimensionada de ambos factores (puesto que la ceremonia incluye, en cierta forma, tanto la embajada como la procesión), es susceptible, por consiguiente, de ser observada también como parte de esta ritualidad.

De hecho, la imagen que, en este sentido, debemos conservar de la ciudad bajomedieval -y tomamos aquí a Barcelona como ejemplo- es la de un espacio con múltiples lecturas (física, jurídica, económica, cultural, religiosa...) en el cual el rey podía, o no, entrar muchas veces - con o sin fiesta - , y que, a su vez, era capaz de recibir a otras personalidades - con o sin fiesta- que no eran ni el rey ni su familia, mientras que, en ocasiones, era el propio monarca, ya dentro de la ciudad, quien se encargaba de acoger al visitante que se acercaba a ella ${ }^{8}$. Ceremonias todas ellas de entrada en la ciudad, con mayor o menor intensidad escénica, que manifiestan la existencia de una práctica más amplia y general, de la cual vendrían a formar parte las entradas reales. El estudio de éstas últimas, desde dicha perspectiva, debería conceder mayor atención a la identificación de los códigos ceremoniales urbanos que al propio ritual de la realeza. En otras palabras, quizá sería más interesante y productivo contemplar la entrada real como una "ceremonia de recepción urbana" antes que como una manifestación deudora del ceremonial monárquico. No ha de olvidarse, en definitiva, que es la tensión generada por el encuentro entre ambos factores lo que concede a la entrada real su verdadero sentido, más allá de las imágenes espectaculares o del brillo de su escenificación, en tanto que expresión creativa y dinámica, social y política,

ejecuta todo gesto en el cual esté implicada institucionalmente la universitas (Véase Rúbriques de Bruniquer. Ceremonial dels Magnifichs Consellers y Regiment de la Ciutat de Barcelona, 5 vols., Colecció de Documents Històrichs Inèdits del Arxiu Municipal de la Ciutat de Barcelona, 19121916). En el mismo sentido, pueden consultarse, en relación a otras localidades catalanas, Antoni VILA, Cerimonial de Consellers de la ciutat de Vic. Manuscrit inèdit del segle XV, Vic, 1989; Miquel PuJOL CANELLES, El Cerimonial dels Consols de la Universitat de Castelló d'Empúries, "Annals de l'Institut d'Estudis Empordanesos", 30 (1997), pp. 205-272.

${ }^{8}$ Los dietarios municipales barceloneses de los siglos XIV y XV constituyen una fuente de inapreciable valor a la hora de detectar toda esta actividad ceremonial. Véanse Crònica del Racional de la Ciutat de Barcelona, "Recull de Documents i Estudis", I (1921), pp. 113-192, para el período que va desde 1334 hasta 1417; Manual de Novells Ardits, vulgarment apellat Dietari del Antich Consell Barceloní, 28 vols., Barcelona, 1892-1992, en concreto los volúmenes 1, 2 y 3 , para el período comprendido entre 1390 y 1533 . Es igualmente útil el Dietari de la Deputació del General de Cathalunya, CODOIN, vols. XLVI y XLIX, Barcelona, 1974 y 1977, que cubre el período entre 1411 y 1512 (o su edición actualizada en Josep Maria SANS I TRAVÉ, Dietaris de la Generalitat de Catalunya, vol. 1, Barcelona, 1994). 
en la que entra en juego, a diferentes niveles, el conjunto de la sociedad medieval ${ }^{9}$.

La asunción de este presupuesto teórico aparece íntimamente relacionada $-\mathrm{y}$ entramos ahora en el terreno de la metodología - con una manera diferente de abordar el estudio de la entrada real, normalmente centrado - ya sea por las exigencias que impone, en muchos casos, la documentación disponible, o por la propia fascinación que en el historiador crea el impactante despliegue visual de esta ceremonia ${ }^{10}$ - en la estricta materialización del evento. La investigación en los aparentes márgenes de la celebración, llevando la atención hacia todo aquello que la anticipa (es decir, su proceso de gestación) o que la prolonga en el tiempo (tanto la existencia de gestos inacabados o diferidos como la conservación del ritual en la memoria institucional, tanto real como municipal), no únicamente acaba resaltando de manera inevitable el protagonismo de la ciudad, sino que muestra igualmente en qué medida estos mismos márgenes resultan indispensables para poder acceder a un verdadero conocimiento de la entrada real. A raíz de ello, el papel de la ciudad se dinamiza, el decorado se activa y, finalmente, el escenario tiende a dejar ver lo que se esconde tras él. El "diálogo" que, a través de la configuración de la ceremonia y de los gestos que tienen lugar en ella, puede intuirse entre monarca y municipio ${ }^{11}$, aparece ahora en su forma más literal, llegando incluso, en ocasiones, a adquirir el grado de "negociación".

${ }^{9}$ Para Lawrence M. Bryant, «A chaque époque, l'ensemble des célébrations est le resultat de la sélection et du pouvoir créatif de la communauté des participants et non la répétition continue de formules rituelles» (L.M. BRYANT, La cérémonie de l'entrée, p. 515).

${ }^{10}$ Un aspecto, éste último, mucho más perceptible en la historiografía dedicada a la entrada real en la Edad Moderna, y que, de rebote, parece haber acabado afectando a los medievalistas. En palabras de Gordon Kipling: «The Renaissance triumph à l'antique has become for us a kind of Platonic idea of civic triumph which medieval processions can never achieve» (G. KIPLING, Enter the King, p. 10).

${ }^{11} \mathrm{El}$ término ha sido utilizado, entre otros, por B. GUENÉE, Les entrées royales, p. 8; L.M. BRYANT, La cérémonie de l'entrée, p. 515; y N. MOSSELMANS, Les villes face au prince, p. 534. 
En este orden de cosas, la elección de la figura de Juan II $^{12}$ y de su primera visita a Barcelona como rey de la Corona de Aragón como tema de estudio no obedece a un mero capricho, puesto que el reinado de este monarca (1458-1479) viene a romper cualquier idea preconcebida o demasiado cómoda respecto a la ceremonia de entrada real. Si alguna vez existió un ritual fijo y definido para este tipo de acontecimientos en la Barcelona bajomedieval -en su sentido más estricto, aquél que acompañaba la celebración solemne de la primera entrada que el rey, la reina o el primogénito al trono realizaban como tales en la ciudad ${ }^{13}-$, éste pareció volatilizarse, en cierta manera, a lo largo de dicho período. Entradas iniciáticas (en 1458), victoriosas (en 1472, tras la capitulación de la ciudad que ponía punto final a la Guerra Civil iniciada en 1462) y triunfales (en 1473, tras la campaña militar contra Francia en el Rosellón) del propio soberano convivieron con recepciones duplicadas a primogénitos reconocidos (el infante Fernando, futuro Fernando II de Aragón, en 1461 y 1473) y no reconocidos (el Príncipe de Viana, en 1460 y 1461), y se vieron desplazadas por la acogida dispensada a los llamados "reyes intrusos" o a sus lugartenientes durante aquel tiempo en que el propio Juan II fue declarado enemigo en Cataluña (Pedro de Portugal, en 1464; Juan de

\footnotetext{
${ }^{12}$ Definido por Eloísa RAMírez VAQuero, La reina Blanca y Navarra, "Príncipe de Viana", 217 (1999), p. 324, como «la personalidad sin duda más arrolladora del siglo XV peninsular, y una de las más singulares de todo el Occidente europeo», Juan II es propietario de una cambiante figura institucional, difícil de concretar: infante de Aragón en oposición incansable y obsesiva hacia la rama Trastámara reinante en Castilla, rey de Navarra desde 1425, soberano de la Corona de Aragón tras la muerte de Alfonso el Magnánimo en 1458, llegó también a desempeñar los cargos de Lugarteniente y Gobernador General en Aragón, Valencia y Cataluña. Fruto de todo ello, su trayectoria ofrece sobrados alicientes para el estudio de la significación política de lo ceremonial. Para todo lo relacionado con este monarca, véanse, entre otros, Jaime VICENS VIVES, Juan II de Aragón (1389-1479). Monarquía y revolución en la España del siglo XV, Barcelona, 1952 (nueva edición en Pamplona, 2003); IDEM, Els afers castellans de Joan II de CatalunyaAragó, "Butlletí de la Societat Catalana d'Estudis Històrics", I (1952), pp. 17-24; Eloy BENITO RUANO, Los Infantes de Aragón, Madrid, 1952 (nueva edición en Madrid, 2002); José Ramón CASTRO, Blanca de Navarra y Juan de Aragón, "Príncipe de Viana", 102-103 (1966), pp. 47-63; Joseph CALMETTE, Louis XI, Jean II et la révolution catalane (1461-1473), Ginebra, 1977 (edición original en 1902); ${ }^{\mathrm{a}}$ Isabel OstolAZA, D. Juan de Aragón y Navarra, un verdadero príncipe Trastámara, "Aragón en la Edad Media", XVI (2000), pp. 591-610; Julio VALDEÓN, Los Trastámaras. El triunfo de una dinastía bastarda, Madrid, 2001.

${ }^{13} \mathrm{Tal}$ como aparece recogido en el Llibre del Consell barcelonés: «...la ciutat no havia acustumat fer festa a senyor per rahó de coronació, ne a I senyor més avant de una festa, la qual se fehia en sa novella entrada, fos coronat o no fos coronat...» (AHCB, CC, Llibre del Consell, XXVIII, f. 9v. 1400, marzo, 27. Barcelona). Para más detalles sobre esta argumentación, esgrimida por los regidores municipales ante la segunda visita de Martín el Humano a Barcelona, tras su entrada real de 1397 en dicha ciudad, y después de haberse coronado en 1399 en Zaragoza, véase Miguel RAUFAST CHICO, ¿Un mismo ceremonial para dos dinastías? Las entradas reales de Martín el Humano (1397) y Fernando I (1412) en Barcelona, "En la España Medieval", 30 (2007) (en vías de publicación).
} 
Lorena y Juan de Calabria, en representación de Renato de Anjou, en 1467 y 1471, respectivamente). Un verdadero y variado mosaico ceremonial que, entre otros aspectos, muestra la profunda relación del ritual de recepción urbano con la realidad social y política dentro del cual es escenificado, además de patentizar, de forma concluyente, el activo protagonismo institucional de la ciudad ${ }^{14}$.

En cuanto a la atención priorizada sobre la entrada real de Juan II en Barcelona en 1458, ésta queda plenamente justificada tanto por las circunstancias que provocaron que su gestación fuera larga y algo compleja, como por la numerosa documentación que, en torno a todo ello, se generó en su momento y se conserva en la actualidad. Primera entrada solemne de Juan II de Aragón en Barcelona ${ }^{15}$, pero también primera entrada solemne que se realizaba en la ciudad desde tiempos de Fernando I (1412) - puesto que la entrada de Alfonso el Magnánimo, en 1416, careció de todo componente festivo en señal de duelo por la aún muy reciente muerte del mencionado Fernando $\mathrm{I}^{16}-$, su celebración, inicialmente prevista para agosto de 1458 , pero no materializada hasta finales de noviembre de ese año, obligó a unos y otros a un ejercicio de memoria y pesquisa, no siempre exitoso, en busca de precedentes ceremoniales a utilizar como modelos. Esto, unido a la habitual tipología documental, tanto municipal como cancilleresca, en que solían quedar reflejados dichos eventos, nos proporciona una información que, tanto por su calidad como por su cantidad, permite no sólo reconstruir el esquema

${ }^{14}$ Un protagonismo que adquirirá su máximo exponente en las ya mencionadas entradas reales de Pedro de Portugal, en 1464, y de los lugartenientes de Renato de Anjou, en 1467 y 1471 , totalmente dominadas por la voluntad de los regidores municipales y desarrolladas en inusuales puestas en escena, en las cuales los visitantes, más que salvadores del reino, parecían marionetas a disposición de las decisiones ceremoniales de la ciudad. Para una descripción de dichas entradas, véanse Agustí DURAN I SANPERE; Josep SANABRE, Llibre de les Solemnitats de Barcelona, 2 vols., Barcelona, 1930-1947, vol. 1, pp. 274-277 (Pedro de Portugal) y 286-293 (Juan de Lorena); Dietari de la Deputació, vol. II, pp. 111-112 (Juan de Calabria).

${ }^{15}$ Juan II ya había sido recibido por la ciudad de Barcelona en ocasiones anteriores, previamente a su acceso al trono de la Corona de Aragón, en calidad de miembro de la familia real o de Lugarteniente General del reino, pero nunca con la trascendencia ceremonial que implicaba una entrada real. A efectos comparativos, puede consultarse la descripción que de su entrada en la ciudad, en 1454, como Lugarteniente General de Cataluña, se conserva en el Llibre de les Solemnitats, vol. 1, pp. 208-209.

${ }^{16}$ «Dissabte, a XXX de maig MCCCCXVI, entrà en Barchinona lo senyor rey don Alfonso, qui novament succehia al rey en Fferrando, pare seu, e vench vestit de gramalla de molada; fonch reebut simplament, sens festa alguna»(Josep $\mathrm{M}^{\text {a }}$ SANS I TRAVÉ, Dietari o Llibre de Jornades (1411-1484) de Jaume Safont, Barcelona, 1992, p. 7). Dicha circunstancia quedaría compensada, en parte, con el recibimiento, esta vez sí festivo y solemne, con el que la ciudad acogió a Alfonso IV en 1423, a su regreso de su frustrada primera experiencia en el reino de Nápoles (véase A. DURAN, Llibre de les Solemnitats, vol. I, pp. 1-8). 
básico sobre el que se sustenta la escenificación de la entrada real en la Barcelona bajomedieval -recibimiento previo fuera de las murallas, entrada en la ciudad, juramento por parte del monarca de los privilegios y libertades del municipio, desfile de oficios y entremeses, recorrido urbano bajo palio, visita a la iglesia principal, celebración de justas y concesión final de un donativo económico al soberano ${ }^{17}-$, sino también asistir al proceso mediante el cual ésta es concebida, debatida, elaborada y, finalmente, ultimada.

Así, a la descripción explícita que, de la entrada real de Juan II en Barcelona el 22 de noviembre de 1458, puede hallarse en los dietarios de la época ${ }^{18}$, ha de añadirse la importante documentación archivística derivada de tal acontecimiento, y de la cual ha quedado constancia tanto en el Archivo de la Corona de Aragón como, muy especialmente, en el Archivo Histórico de la Ciudad de Barcelona.

El primero, a través de los registros de Cancillería, da fe del interés del monarca acerca del ritual de la entrada, desde los muy iniciales tanteos en torno a su celebración hasta los detalles que habrán de concluirla.

El segundo, gracias al material suministrado por los subfondos Consell de Cent y Consellers, evidencia, de forma irrebatible, el verdadero papel jugado por la ciudad en todas las diferentes etapas de la ceremonia: las series Lletres closes y Lletres reials originals muestran al municipio en diálogo literal con el soberano meses antes de que tenga lugar la propia entrada real, mientras que las Lletres comunes tienden a revelar la capacidad de Barcelona para estar informada casi permanentemente de la situación exacta del rey antes de su llegada a la ciudad. Por su parte, los registros de Deliberacions constituyen la fuente básica para observar el funcionamiento del órgano rector del municipio en relación a dicha celebración: mediante las propuestas de los consellers, las reuniones del Consell de XXXII (o

${ }^{17}$ Es posible encontrar una aproximación a los elementos de dicho esquema, aunque sea a partir de la utilización de referencias tanto bajomedievales como pertenecientes al siglo XVI, en Lenke KovaCS, La ciutat com a escenari: les entrades reials $i$ la festa urbana, "Barcelona. Quaderns d'Història", 9 (2003), pp. 71-82.

${ }^{18}$ Véanse Manual de Novells Ardits, vol. II, pp. 294-295; Dietari de la Deputació, vol. XLIX, pp. 3-5. Lamentablemente, el Llibre de les Solemnitats de Barcelona, destinado, desde su inicio a finales del siglo XIV, a recoger todas aquellas ceremonias y actos solemnes de la ciudad que, por su importancia y trascendencia, merecían y aconsejaban una descripción en extenso y detallada, no incluye, tal como se conserva en la actualidad, ninguna referencia a dicha entrada. 
Trentenari $)^{19}$ y las aprobaciones del Consell de Cent, la preparación de la ceremonia cobra forma y todos los temas son puntillosamente contemplados, desde el color de una tela hasta la repercusión económica que para las arcas del municipio supondrá la visita del rey. Algunos de dichos gastos - desde los pagos a los carpinteros que trabajaron en la construcción del catafalco destinado a Juan II hasta el coste de las antorchas que habían de servir para iluminar el recorrido del monarca por la ciudad o el alquiler de un caballo para las justas que tuvieron lugar en el Born, por citar tan sólo algunos ejemplos - aparecen recogidos en los registros de Clavaria, Obreria y Correu $i$ menut. Por último, las disposiciones finales de los regidores municipales en torno a la fiesta solemne quedan reflejadas en los registros de Ordinacions, y también, obviamente, en la serie Ordinacions originals, donde se encuentran las crides públicas que se hacían a la población de Barcelona, anunciando la inminente celebración de la entrada del monarca ${ }^{20}$.

De entre todas las posibilidades que ofrece esta variada documentación, y por razones que tienen que ver básicamente con la inviabilidad de tratarlas todas ellas en un artículo de estas características, nos hemos decantado por destacar un aspecto que, además de poco o nada conocido, consideramos fundamental para poder entender el significado esencial de la entrada real, esto es, todo aquel proceso previo - llámese "diálogo" o "negociación" - en el cual va cobrando forma la ceremonia a partir de la interacción entre las fuerzas - a grandes rasgos, la ciudad y el monarca ${ }^{21}-$

\footnotetext{
${ }^{19}$ Representación reducida del Consell de Cent y compuesto por miembros de dicho organismo que se iban relevando cada tres meses, el Trentenari actuaba junto a los consellers como órgano delegado de dicho Consell. Para todo lo relacionado con el funcionamiento y organización del gobierno municipal de Barcelona en el siglo XV, sigue siendo vigente el trabajo de Jaume VICENS VIVES, Ferran II $i$ la ciutat de Barcelona, 1479-1516, 3 vols., 1936, vol. I, pp. 106-141. Igualmente, puede consultarse la tesis doctoral inédita de $\mathbf{M}^{\mathrm{a}}$ Asunción BALDRICH ForTuny, El gobierno de la ciudad de Barcelona en la época de Alfonso el Magnánimo (Desde el año 1416 hasta el año 1432), 2 vols., Universitat de Barcelona, 1993, vol I, pp. 191-217.

${ }^{20} \mathrm{El}$ interés añadido de éstas últimas reside en el hecho de que, en su calidad de copias de trabajo dadas al cridaner de la ciudad para ser leídas por los lugares más señalados del municipio, contienen todo tipo de correcciones que, al rectificar el texto inicial, aportan una valiosa información sobre decisiones modificadas a última hora o sobre propuestas alternativas nunca materializadas.

${ }^{21}$ En realidad, por lo que se refiere a la época bajomedieval, tanto la ciudad de Barcelona como el soberano sufrían de una realidad mucho más compleja que, al mismo tiempo que los interrelacionaba, afectaba sustancialmente el aparente equilibrio de sus respectivas identidades. Capaz de entrar en colisión con el monarca para defender la propia jurisdicción real, la imagen compacta que la universitas podía proyectar hacia el exterior se sustentaba, de hecho, sobre un complicado entretejido de tensiones sociales y divergencias grupales internas. Por lo que respecta al rey, su relación con la ciudad era mucho más intensa y determinante de lo que pudieran hacer pensar sus repetidas y, en algunos casos, constantes ausencias: protagonista, creador y garante
} 
que participan en su creación. Somos conscientes de que puede resultar paradójico - y mucho más ante la constatación de la práctica inexistencia de estudios sobre la entrada real en la Barcelona bajomedieval ${ }^{22}$ - privilegiar los preámbulos de la celebración antes que la descripción de la entrada en sí o la identificación de sus elementos, pero ha de entenderse, tal y como hemos venido manteniendo a lo largo de nuestra argumentación, que son este tipo de "márgenes" los que, facilitando la interpretación institucional y política de la ceremonia, habrán de contribuir decisivamente a una mejor comprensión posterior de sus detalles físicos y materiales ${ }^{23}$.

\section{ESPERANDO AL NUEVO REY}

Pero ¿cómo fijar el momento exacto en que empieza una historia? Todo ha empezado siempre ya antes, la primera línea de la primera página de toda novela remite a algo que ha sucedido ya fuera del libro. O bien la verdadera historia es la que empieza diez o cien páginas más adelante y todo lo que precede es sólo un prólogo. Las vidas de los individuos de la especie humana forman una maraña continua, en la cual todo intento de aislar un trozo de lo vivido que tenga sentido por separado del resto - por ejemplo, el encuentro de dos personas que resultará decisivo para ambasdebe tener en cuenta que cada una de las dos lleva consigo un tejido de

del régimen de funcionamiento municipal, representado permanentemente en ella por oficiales delegados como el batlle o el veguer, no era nunca alguien ajeno, ni física ni institucionalmente, a la existencia cotidiana de la urbe, por mucho que no hubiera atravesado sus murallas en años. Para algunas interesantes reflexiones sobre estos aspectos, véanse Flocel SABATÉ, Lo senyor rei és mort, Lérida, 1994;IDEM, Municipio y monarquía en la Cataluña bajomedieval, "Anales de la Universidad de Alicante" (Historia Medieval), 13 (2000-2002), pp. 255-281; Pere ORTí IGOST, Renda $i$ fiscalitat en una ciutat medieval: Barcelona, segles XII-XIV, Barcelona, 2000, especialmente las pp. 42-43.

${ }^{22}$ Nos atreveríamos únicamente a mencionar el trabajo de Teresa VinYOLES, Festes $i$ "alegries" baixmedievals, "Revista d'Etnologia de Catalunya", 13 (1998), pp. 42-61; y la tesis doctoral inédita de Kenneth KreITNER, Music and Civic Ceremony in Late Fifteenth Century Barcelona, Duke University, Durham, 1990. Por lo que respecta a la Edad Moderna, la entrada real en Barcelona sí ha sido objeto de una mayor consideración. Véanse, especialmente, $\mathbf{M}^{\mathrm{a}}$ Ângels PÉREZ SAMPER, El rey y la ciudad. La entrada real de Carlos I en Barcelona, "Studia Historica”, 6 (1988), pp. 439-448; L. KovACS, La ciutat com a escenari.

${ }^{23}$ Este artículo ha de ser contemplado, por tanto, como una inicial contribución al estudio de la entrada real en la Barcelona bajomedieval que será ampliada en próximos trabajos, en los cuales han de ir apareciendo aspectos no tratados aquí (economía, alojamiento, itinerarios urbanos, religiosidad, etc.), y que esperamos poder culminar en nuestra futura tesis doctoral, Entradas reales y ceremonias urbanas de recepción en la Cataluña bajomedieval. 
hechos, ambientes, otras personas, y que del encuentro se derivarán a su vez otras historias que se separarán de su historia común ${ }^{24}$.

El 16 de julio de 1458, la ciudad que había esperado durante más de 20 años el regreso de Alfonso el Magnánimo supo que el monarca ya nunca la visitaría de nuevo, al conocer que éste acababa de morir en Nápoles ${ }^{25}$. La noticia, transportada por un correo, informaba del fallecimiento del rey el 27 de junio, confirmando un desenlace que unos y otros parecían contemplar como inminente $^{26}$. El 14 de junio, Alfonso IV había solicitado a su archivero real en Barcelona que le enviase, secretament, una copia del testamento de su padre, Fernando $\mathrm{I}^{27}$. Barcelona, por su parte, había celebrado una procesión, el 23 de junio, per la recuperació de la sanitat de la reyal persona del molt alt e molt excel lent senyor, lo senyor rey, en la salut e longua vida del qual sta lo benefici, repòs e tranquille stat de la república de sos regnes e terres ${ }^{28}$. En apenas unas horas, la ciudad, el reino, pasaban de la incerteza al dolor, y de éste a la alegría. Sentimientos institucionalizados todos ellos, convenientemente instalados en el protocolo, que habían de permitir compaginar los actos funerarios por el monarca fenecido con las muestras de alegría destinadas a festejar el nombramiento y la futura visita del nuevo rey. En un mismo día, el 17 de julio, los consellers decidían escribir a Juan II, saludándolo como soberano, al tiempo que se envolvían en el duelo fúnebre por la memoria de su hermano ${ }^{29}$.

${ }^{24}$ Italo CALVINO, Si una noche de invierno un viajero, Madrid, 1999, p. 165.

${ }^{25}$ Como es bien sabido, Alfonso IV había partido de Barcelona hacia tierras italianas en 1435 y su ausencia de los reinos peninsulares, tras la conquista de Nápoles, se acabaría prolongando indefinidamente hasta su muerte en 1458.

${ }^{26}$ «...hir, entre les VI e VII hores aprés migjorn, arribà en aquesta ciutat un correu qui aportà letras de mossèn Arnau Fonolleda dreçades a diverses poblats en aquesta ciutat, per les quals, ab tota certitud, és sabuda la mort del molt alt e molt excel·lent nostre rey e senyor, la qual nova és de gran congoixa e dolor...» (AHCB, CC, Deliberacions, II-12, f. 40r-v. 1458, julio, 17. Barcelona).

${ }^{27}$ «...reebut que haureu la present, ab assídua diligència cerqueu en lo nostre archiu lo testament del sereníssimo senyor rey don Ferrando, de gloriosa recordació, pare nostre, e de aquell façau de vostra mà còpia autèntica, la qual, interclusa en letra vostra, trametreu a nostre prothonotari, mossèn Arnau Fonolleda, e açò fareu secretament, no comunicant-ne ab persona alguna...» (ACA, Colección H, caja 2, carta 507. 1458, junio, 14. Castelnuovo de Nápoles).

${ }^{28} \mathrm{AHCB}, \mathrm{CC}$, Ordinacions, IV-8, f. 64v. 1458, junio, 22. Barcelona.

${ }^{29}$ «...fou delliberat e conclòs que, per part de aquesta ciutat, ne fos scrit al senyor rey de Navarra, intitulant-lo rey d'Aragó (...) e, noresmenys, fou delliberat que fos fet un solempne aniversari per ànima del dit senyor en la forma e manera que per aquesta ciutat, en lo passat, per ànima dels altres reys de Aragó, de loable memòria, és stat acustumat» (AHCB, CC, Delibera- 
Por lo que respecta al nuevo rey - en ese momento en el reino de Navarra-, la luctuosa nueva había llegado hasta Tudela el 15 de julio ${ }^{30}$, desencadenando la puesta en marcha del mecanismo de sucesión que conduciría a Juan II inmediatamente a Zaragoza para jurar como soberano ${ }^{31}$. Tras entrar en esa ciudad el 22 de julio ${ }^{32}$, tres días más tarde, el 25 de julio, tenía lugar la ceremonia que formalizaba su entronización ${ }^{33}$. Ese mismo día, una carta real partía hacia Barcelona informando de lo acontecido y solicitando de la ciudad su implicación en la celebración de las exequias por el alma de Alfonso IV ${ }^{34}$. En perspectiva, aparecían las obligadas visitas al resto de reinos peninsulares de la Corona - Cataluña y Valencia-, en un largo periplo de juramentos y ceremonias, unas más modestas que otras, que extenderían, en cierto sentido, la toma de posesión hasta febrero de 1459.

Estos aspectos han de ser tenidos en cuenta, puesto que la entrada que se pretende analizar aquí, la de Juan II en Barcelona el 22 de noviembre de 1458, comienza, en realidad, mucho antes de dicha fecha, y lo que seduce de su estudio es, precisamente, la posibilidad de mostrar cómo su celebración se gesta en la distancia y en qué forma su desenlace es, en ocasiones, fruto de las circunstancias o, tal vez, de calculadas estrategias camufladas en forma de

cions, II-12, f. 40r-v. 1458, julio, 17. Barcelona).

${ }^{30}$ Jaime VICENS VIVES, Juan II, p. 181.

${ }^{31}$ Tal como señala José $\mathrm{M}^{\mathrm{a}}$ de FRANCISCO OLMOS, La figura del heredero al trono en la España Medieval, Madrid, 2003, p. 158: «La sucesión sólo tiene carácter forzoso para hijos y hermanos del monarca, fuera de éstos el rey o/y el Reino parecen tener libertad para elegir entre los demás parientes del monarca. Los hijos son llamados por el orden de su nacimiento, y a falta de ellos los hermanos del monarca en el mismo orden, asentándose sólidamente el principio de primogenitura».

${ }^{32}$ Dietari del Capellá d'Anfos el Magnànim (edición de Josep SANCHIS I SIVERA), Valencia, 1932, p. 223.

${ }^{33}$ Hay que recordar que, tras Fernando I, en 1412, ni Alfonso IV, ni Juan II, tuvieron una coronación de carácter litúrgico. Sobre este tema, véase Antonio DURÁN GUDIOL, El rito de la coronación del rey en Aragón, "Argensola", 103 (1989), pp. 17-39; Víctor FERRO, El Dret Públic Català. Les institucions a Catalunya fins al Decret de Nova Planta, Vic, 1987, pp. 31-34.

${ }^{34}$ «E per aquesta causa nós som venguts en aquesta nostra ciutat de Çaragoça, on, ab molt gran obediència e honorificiència, som stats rebuts per los magnats e altres persones de tots los staments que en aquella se són trobats, e havem prestat públicament en la Seu de la dita ciutat lo jurament que per los il·lustríssimos reys d'Aragó, predecessors nostres, (...) és stat acostumat fer e prestar, e apparellam la solemnitat de les exèquies reyals que per lo dit senyor rey, nostre frare, per nós deuen ésser fetes. E, per tant, vos pregam e encarregam, axí secretament com podem, que vosaltres, axí mateix, façats per lo dit senyor rey les exèquies acostumades en casos semblants com a rey e senyor natural vostre...» (AHCB, CC, Lletres reials originals, IX-3, carta 746. 1458, julio, 25. Zaragoza. También en ACA, C, reg. 3441, f. 9r). 
azar, frente a esa imagen irreal y perfecta, casi predestinada, que de las ceremonias de entrada real suelen ofrecer las fuentes cronísticas.

En el caso que nos ocupa, la entrada de Juan II en Barcelona pareció, por un momento, encaminada a ser un calco de la apagada ceremonia que acompañó a Alfonso el Magnánimo en su primera visita como monarca a la ciudad en 1416, y acabó siendo una fiesta inspirada en la acogida que recibió Fernando I en 1412. Un asunto de tiempo, salteado de pequeñas "negociaciones" y continuo diálogo, que modificó sustancialmente la recepción y, al mismo tiempo, la dotó de un significado más potente y expresivo. Al mismo tiempo, la demora del rey, retenido en Zaragoza por diferentes eventualidades, no apuntaba únicamente hacia Barcelona, sino que integraba el conjunto de localidades que éste preveía visitar en el periplo inaugural de su reinado.

Etapa trascendente en dicho viaje, el cap i casal del Principado había de compartir la atención de Juan II con ciudades como Lérida, que la precedía en el trayecto, o Valencia, que la seguía en dicho itinerario. Entremedio, poblaciones como Balaguer, Agramunt, Tárrega, Cervera, Igualada o Montblanc (véase fig. 1) que también esperaban la llegada del soberano y decidían sus respectivos ceremoniales, inspirándose tanto en su propia tradición como en la práctica que ahora había tenido lugar o se pensaba llevar a cabo en el resto de municipios ${ }^{35}$. Barcelona no era ajena a este espionaje ampliamente aceptado, y determinadas decisiones sobre los actos que compondrán la fiesta de recepción real de 1458 tendrán que ver con lo acontecido anteriormente en Zaragoza ${ }^{36}$ o en Lérida $^{37}$. Tortosa y Valencia, por

${ }^{35}$ «Al Principat, els models bàsics a imitar seran, per a les poblacions de Cervera i Tàrrega, els de Lleida i els de Barcelona; així, la tramesa de síndics a Lleida o a Barcelona -segons l'indret d'on vinguin els reis- per veure com s'ha desenrotllat la recepció als reis serà una pràctica coneguda, si no habitual» (R. MIRÓ, Fasts reials a Tàrrega, p. 133). La práctica no se reduce a las entradas reales, sino que afecta a todo tipo de ceremonias institucionales, como ha mostrado F. SABATÉ, Lo senyor rei és mort, p. 255, en relación a los actos funerarios: «El 1458 els governants locals de Girona volen saber exactament com els homòlegs de Barcelona pensen honorar la mort del Magnànim, i per això els pregunten com faran les exèquies, plantejant una exhaustiva bateria de qüestions...»

${ }^{36} \mathrm{El} 2$ de agosto de 1458, el Consell decidía enviar a Pere Destorrent a Zaragoza para entrevistarse con Juan II y que, a su regreso, informase del «rehonament haüt per ell ab lo dit senyor en diverses voltes, e la entrada e jurament per lo dit senyor rey fets en la ciudad de Çeragoça, e la pràticha e forma allí tenguda, e moltes altres coses per lo dit mossèn Pere Deztorrent vistes e sentides...» (AHCB, CC, Deliberacions, II-12, f. 42r. 1458, agosto, 2. Barcelona).

${ }^{37} \mathrm{El} 16$ de noviembre de 1458, el conseller Pere Serra comunicaba al Consell que la ciudad de Lérida había dispuesto un premio para las justas celebradas con motivo de la entrada de Juan II: «...fou exposat per lo honorable mossèn Pere Serra, un dels consellers, en nom de tots, com era cert que en la ciutat de Leyda, en la qual eren stades fetes junctes per la entrada del senyor 
su parte, quedaban a la espera de tener noticias sobre lo sucedido en Barcelona, mientras intentaban precisar con exactitud tanto la situación exacta del monarca en su itinerario, como sus previsiones inmediatas respecto al desarrollo del viaje ${ }^{38}$. Cartas, correos, noticias y mensajeros que entrecruzaban sus caminos, estableciendo una red que conectaba, definía y jerarquizaba el territorio ${ }^{39}$, al mismo tiempo que lo ponía en contacto con el soberano a través de un ceremonial perpetuo que superaba los estrictos límites de cada entrada. Mientras Juan II, tras su llegada a Lérida, contemplaba los juegos taurinos con que dicha ciudad le obsequiaba ${ }^{40}$, los consellers de Barcelona debatían la forma más adecuada y menos gravosa de costear la futura recepción al rey ${ }^{41}$, al tiempo que en Igualada ya se había decidido qué ofrenda le sería hecha por su visita ${ }^{42}$. De la misma forma, mucho después de concluida la ceremonia en Valencia ${ }^{43}$, todavía no se había hecho efectiva la entrega del

rey, era stada posada una baçina d'argent de pes de VIII marchs al qui millor junyiria, e per quant era creegut que si aquesta ciutat no posave axí mateix algun pris, que forts pochs exirien per junyir...» (Ibídem, f. 59v. 1458, noviembre, 6. Barcelona).

${ }^{38} \mathrm{El} 11$ de diciembre de 1458, en el Consell de Tortosa se certificaba la próxima visita de Juan II y se comenzaba a preparar su recepción, la cual no tendría lugar hasta finales de enero de 1459: «...com és avisat que lo senyor rey s.ich spera prestament ací, e diu que és de passada per anar a València (...) Sobre la festa que's farà sobre la venguda e nova intrada del dit senyor, fon provehit que dos o tres dies se'n farà festa, e que tot pose lo dol, e que la ciutat sia empaliada e enramada...» (AHCTE, Provisions, 48, f. 26r-v. 1458, diciembre, 11. Tortosa).

${ }^{39}$ En el mismo sentido se ha expresado F. SABATÉ, Lo senyor rei és mort, p. 255, en referencia a los cauces habituales de difusión de la muerte de los monarcas: «Mentre la transmissió de la notícia de la defunció reial referma les xarxes de capitalitat regional, les disquisicions sobre els actes a celebrar refermen els lligams entre afins i similars».

${ }^{40}$ AML, Cerimonial Antich, reg. 700, f. 49r. 1458, noviembre, 6. Lérida. El documento aparece transcrito en Carme BATLlE; Joan J. BUSQUETA, Príncipe y ciudades en la Corona de Aragón en el siglo XV, en Sergio GENSINI (ed.), Principi e città alla fine del Medioevo, Pisa, 1996, pp. 333-356.

${ }^{41}$ «...fon proposat en lo dit Concell com ells, consellers, havien trobada forma e manera ab les quals les despeses fahedores per rehó de la dita festa serien paguades sens inposar algun dret, ço és, que fossen remuts alguns dels censals que la ciutat fa, assignant a la Taula de la ciutat les pensions dels dits censals que-s rembran» (AHCB, CC, Deliberacions, II-12, f. 57v. 1458, noviembre, 6. Barcelona).

${ }^{42}$ «...que per rahó de la novella entrada ara faedora per lo molt alt senyor, lo senyor rey en Johan, ara benaventuradament regnant, sie fet servey al dit senyor rey de capons, é de gallines, é vins, é fruytes, fins en valor de deu florins dor poch més, o menys...». Reproducimos aquí la noticia, fechada el 3 de noviembre de 1458, que transcribe Joan SEGURA, Història d'Igualada, 2 vols. (edición facsímil de la de 1907), Igualada, 1978, vol. I, p. 289.

${ }^{43}$ «En l'any de nostre senyor MCCCCLVIIII., digous, a VIII. de febrer, qui fonch segon dia de quaresma, lo senyor rey don Johan, rey de Aragó e de Navarra, jerma del rey don Alfonso e fill del rey don Ferando e de la reyna dona Hurraqua, entra en la ciutat trihumphosa de Valencia, hon li foren fets molts actes e aparelaments e maneres de grans honors e de grans festes per les gents...» (Dietari del Capellá, p. 224). 
donativo que Barcelona había prometido al monarca con motivo de su primera entrada ${ }^{44}$. Celebraciones, por tanto, inconclusas o aún no materializadas, que se superponían en el tiempo y que, en cualquier caso, no parecían circunscritas a un único escenario.

\section{PreÁmbulos}

A mediados de agosto de 1458, los consellers de la ciudad de Barcelona recibían una carta del recién proclamado rey, desde Zaragoza, recabando información sobre la entrada real que Martín el Humano había realizado en 1397. La misiva, de un marcado detallismo, expresaba el interés de Juan II por saber cómo se había desarrollado aquella celebración en todos sus aspectos: cómo vestía el monarca, quién le acompañaba y de qué forma había sido festejada su presencia. De igual manera, se solicitaba el mismo tipo de información respecto a las ceremonias de recepción de Juan I, Fernando I y Alfonso IV y, muy especialmente, cuánto tiempo había pasado desde la muerte del predecesor de cada uno de ellos hasta el momento de sus respectivas entradas en la ciudad ${ }^{45}$.

El rey preparaba su entrada en Barcelona y, para ello, más que un desarmante desconocimiento respecto de las prácticas de dicho acontecimiento, lo que esgrimía era una estrategia habitual y ampliamente ejecutada a lo largo de todo el siglo XV, mediante la cual se acudía a la memoria institucional para encontrar en la tradición un arma, una defensa o una legitimación ${ }^{46}$.

${ }^{44}$ El 12 de abril de 1459, desde Valencia, Juan II aún seguía solicitando a los consellers de Barcelona el envío de dicho donativo: «...us pregam e encarregam, ab aquella major affecció e voluntat que podem, que cuytats de donar la plata qui-ns enteneu donar en strenes e servei, en manera que la pugam haver açí en València...» (AHCB, CC, Lletres reials originals, IX-3, carta 775. 1459, abril, 12. Valencia).

${ }^{45}$ «Pregam e encarregam-vos, molt affectuosament, que, vista la present, de continent vos informets quina recepció e festa fonch feta en Barcelona al rey en Martí, frare del rey en Johan, com, aprés mort del dit rey en Johan, venint de Sicília, entrà novellament en aquexa ciutat; e ab quina roba entrà vestit; e quina solempnitat li fonch feta; e quans jorns durà la festa; e com anaven vestits lo dit rey e los curials, axí homes com dones, en la festa e abans e aprés de aquella. $\mathrm{E}$, per semblant, nos certificarets de la recepció del senyor rey don Fferrando, pare nostre, com novament entrà rey de Barcelona. $\mathrm{E}$, axí mateix, del senyor rey don Alfonso, frare nostre, dignes de inmortal memòria. E, encara, del dit rey don Johan. E quant temps passave de la mort del hu a la entrada del altre, e com se regien en portar lo dol los dits reys e reynes...» (AHCB, CC, Lletres reials originals, IX-3, carta 752. 1458, agosto, 13. Zaragoza).

${ }^{46} \ll \mathrm{El}$ valor de la tradició és constant i creixent. A la sortida del segle XV s'insisteix més en realitzar els actes segons la tradició escrita i continguda en els llibres municipals precedents (...). És una actitud generalitzada a tot arreu. En aquest moment, es regiren els llibres antics a gairebé 
La actitud de Juan II no reflejaba únicamente la posible desorientación general que más de cuarenta años de distancia respecto de la última entrada real de un monarca - recordemos, Alfonso IV en 1416- podían generar, sino que, por encima de ella, intentaba oficializar los términos en los que había de plantearse su primera visita a la ciudad. A la búsqueda de los antiguos registros que podían proporcionar un tranquilizador resguardo para la nueva ceremonia, se unía el reconocimiento tácito que el municipio - a través de la obligada respuesta a la solicitud real- hacía del derecho del rey a entrar en la ciudad en las mismas condiciones que sus predecesores.

El contenido de la carta de Juan II no parecía dejar nada al azar. Por un lado, y dada la proximidad de la muerte de Alfonso IV, era necesario conocer en qué circunstancias exactas se habían producido las entradas de los anteriores soberanos y de qué tipo de recepción habían sido objeto. Una posible interpretación de dicho interés sería ésta: si, como en los casos de Juan I y Alfonso IV, se decidía que el recibimiento, por motivo de duelo, careciera de todo elemento festivo, la entrada de Juan II no había de ser nunca "superior" a las de aquéllos; si, por el contrario, al igual que había sucedido con Martín I y Fernando I, tenía lugar una celebración solemne, entonces la entrada de Juan II no podía ser, bajo ningún concepto, "inferior" a las de éstos. En cualquier caso, un manifiesto deseo de obtener, a partir de las prácticas pretéritas, la legitimación de los propios actos, al mismo tiempo que la necesidad de postergar cualquier gesto inapropiado que pudiera mermar el prestigio de la autoridad o la imagen real.

Por otro lado, el especial énfasis puesto en la figura de Martín el Humano, ya habitual en los monarcas Trastámara de la Corona de Aragón, cobraba ahora una importancia y significación particulares ${ }^{47}$. Juan II no trataba únicamente de obtener referentes en el pasado, sino que buscaba hacerlo con la mayor exactitud posible. Un rey que había sucedido a su propio hermano - como era su caso- debía, ante todo, asegurarse de si dicha circunstancia aparecía reflejada en el ceremonial, lo cual, obviamente, pasaba por consultar la recepción tributada por Barcelona al segundo hijo de Pedro el Ceremonioso, llegado al trono tras la muerte de su hermano, Juan I. Tal detallismo y

totes les ciutats i viles reials del país, a la vegada que són molts els llocs que redacten amb detall les cerimònies realitzades, creant-ne llibres especials» (F. SABATÉ, Lo senyor rei és mort, p. 253)

${ }^{47}$ Acerca del interés de Fernando I, en 1412, por asimilar su entrada en Barcelona a la realizada por Martín el Humano en 1397, y también sobre la relación entre la entrada de Juan II en 1458 y las de estos dos monarcas, véase M. RAUFAST CHICO, ¿Un mismo ceremonial para dos dinastías? 
minuciosidad, no exclusivos del monarca ${ }^{48}$, ejemplificaban hasta qué punto el ritual de la entrada real -al igual que otros actos cívicos o religiosos-, a pesar de una identificativa dinámica basada en la repetición y la emulación, no dependía exclusivamente de estos factores y, curiosamente, era capaz de ofrecer en la práctica un notable repertorio de posibilidades y variaciones que, a su vez, mostraban cómo el contenido se imponía a la forma ${ }^{49}$.

Lamentablemente, no disponemos de la respuesta de los consellers de Barcelona a la carta de Juan $\mathrm{II}^{50}$, aunque sí conocemos la que cursaron los diputados del General ${ }^{51}$, quienes también habían sido consultados por el monarca acerca del mismo asunto en esas mismas fechas ${ }^{52}$. En ella, se relataba la infructuosa búsqueda que desde la Diputación del General se había llevado a cabo a través de la memoria institucional de la ciudad (véase doc. 1). Por lo que respectaba a la propia Diputación, nada había sido encontrado en sus estancias - lo cual ponía de manifiesto el limitado protagonismo de la

${ }^{48}$ Una actitud similar fue adoptada, ese mismo año de 1458 , por las autoridades de Barcelona, a raíz de las ceremonias fúnebres por la muerte de Alfonso IV «...els consellers, dubtant què cal fer arran de la mort d'Alfons IV, regiren les escriptures de l'arxiu del consell per tal d'estudiar el comportament en algun cas precedent i semblant a la mort del Magnànim en terres llunyanes deixant com a succesor el seu germà. Així és com troben i prenen de guia l'actuació que fou observada el 1396, en la mort de Joan I, succeït per son germà Martí que residia a Sicília» (F. SABATÉ, Lo senyor rei és mort, p. 31, nota 100).

${ }^{49}$ «La fuerza política de las procesiones nacía de la ficción de inalterabilidad, pero, de hecho, las presiones políticas las alteraban con frecuencia. Después de la primera entrada en París del rey Carlos VIII, en 1484, el tribunal del rey sometió a juicio a la totalidad del Parlamento de París por haber alterado el orden procesional de la delegación que dio la bienvenida al rey en su entrada en la ciudad» (Edward MUIR, Fiesta y rito en la Europa Moderna, Madrid, 2001, p. 298).

${ }^{50}$ No hay, en el Archivo Histórico Municipal, ningún registro de Lletres closes entre 1457 y septiembre de 1458. Sin embargo, sí es posible detectar la existencia de dicha respuesta a través de la carta en la que el rey, dirigiéndose de nuevo a los consellers, acusaba recibo de la que éstos le habían enviado: «Vostres letres de XXI del present mes de agost havem reebudes, responsives a altres nostres que en aquests proppassats dies trameses vos havíem sobre la informació que desijàvem haver de les festes e solemnitats fetes als il-lustríssims reys en Johan, en Martí e don Fferrando, pare, e don Alfonso, germà, nostres, de gloriosa memòria...» (AHCB, CC, Lletres reials originals, IX-3, carta 755. 1458, agosto, 24. Zaragoza. También en ACA, C, reg. 3406, f. $29 v$ ). Prácticamente con las mismas palabras se dirigía el monarca al Gobernador General de Cataluña, Galceran de Requesens, en una carta fechada el 25 de agosto de ese año: «Vostra letra havem reebuda de XXI de agost, ensemps ab les altres que-ns són stades trameses per los consellers de Barcelona e diputats de Catalunya residents en aquella, ab certa informació a nós remesa per los dits consellers sobre les festes e solennitats fetes als reys en Johan, en Martí, don Ferrando, pare, e don Alfonso, germà, nostres...» (ACA, C, reg. 3406, f. 30r. 1458, agosto, 25. Zaragoza).

${ }^{51}$ Delegación permanente de las Cortes catalanas, y con residencia en la ciudad de Barcelona, la Diputación del General, o Generalitat, estaba compuesta, en esta época, por tres diputados y tres oidores de cuentas.

${ }^{52} \mathrm{La}$ carta a los consellers de Barcelona fue emitida el 13 de agosto; la enviada a los diputados del General, el 15 de ese mismo mes. 
institución en este tipo de ceremonias- sobre los detalles que se les solicitaba. Más tarde, las pesquisas en el archivo real de Barcelona habían resultado igualmente estériles y, finalmente, la visita a la Casa de la Ciudad, hon se diu tals actes se acustumen metre en record, se había encontrado con la rotunda negativa de los consellers a compartir dicha información. Incapaces de ir más allá, los diputados habían intentado cumplir el expediente recurriendo a la memoria dels pus ancians e notables cavallers e ciutadans de aquesta ciutat, a partir de cuyos recuerdos particulares habían podido determinar la distancia existente entre las ceremonias de entrada de los reyes anteriores a Juan II y los funerales de sus respectivos predecesores en el trono, llegando a la conclusión de que, para todos ellos, segons la distància dels temps e de les festes o no festes, los vestits de tots eren differenciats en lurs entrades.

En realidad, en este caso, el documento tiene más importancia por lo que no consigue decir que por los escasos datos con los que es capaz de contribuir a la indagación real y, por encima de todo, confirma que el manejo y el acceso a la información confieren $\operatorname{poder}^{53}$ y jerarquía ${ }^{54}$, como así se encargan de evidenciar los consellers de Barcelona, plenamente conscientes de defender la prioridad del gobierno municipal en todo acto cívico que incumba a la ciudad ${ }^{55}$.

Se trata de convertir la memoria humana - aquélla que los diputados del General recogen entre los pus ancians e notables cavallers e ciutadansen tradición y costumbre institucionalizadas a partir de su registro escrito. Y, sobre él, fundamentar todo gesto, duda o decisión que hayan de surgir en el

${ }^{53}$ «Control over the written world in the Middle Ages was always a manifestation of power. Urban documentary practices seem to have competed succesfully with those of local bishops, lords, royal officials, or abbeys in the issuance of authentic deeds» (B. BEDOS-REZAK, Civic Liturgies and Urban Records, p. 39).

${ }^{54}$ «En diferents indrets es cerquen models entorn de comportaments pretèrits similars segons consti en els arxius locals o, també, tal com recordin "alguns ciutadans antichs", bé que l'esterilitat d'aquesta recerca sovint remet, com en el cas de Lleida, a emmirallar-se en Barcelona» (Flocel SABATÉ, La mort d'Alfons el Magnànim: coneixença, divulgació $i$ repercussió de la notícia "XVI Congresso Internazionale di Storia della Corona d'Aragona", Nápoles, 1997, vol. II, p. 1903).

${ }^{55}$ No estaría de más contemplar la posible influencia que el enfrentamiento entre un Consell de Cent dominado en esta época por la Busca y una Diputación claramente proclive a las posturas de la Biga podía tener en todo este asunto. Para la conflictividad social y política en la Barcelona de mediados del siglo XV, véase Carme BATLLE, La crisis social y económica de Barcelona a mediados del siglo XV, 2 vols., Barcelona, 1973. 
futuro. El requisito, más que una necesidad real ${ }^{56}$, forma parte de un ritual legitimador ${ }^{57}$, de un juego de estrategias en el que participan tanto el monarca como la ciudad, y que supone, por lo que se refiere a la celebración de una entrada real, el prólogo imprescindible para la "negociación" que, a su vez, precederá a la ceremonia.

Así, poco antes de que Juan II se dirigiese a los consellers, éstos ya se habían preocupado de buscar protocolariamente en el pasado de la ciudad, previendo una inminente llegada del monarca ${ }^{58}$, en una práctica que, de hecho, podría hacerse extensiva a cualquier otra ciudad bajomedieval, catalana ${ }^{59} \mathrm{o}$ europea $^{60}$. Y casi tres meses después, debido al aplazamiento que retrasó la celebración de la entrada hasta la segunda quincena de noviembre, las sesiones del Trentenari continuaban registrando actividad en este sentido. El 3 de noviembre, en un acto que merece ser reseñado, los consellers habían invitado al notario del racional, Joan Oliver, a acudir a la sala del Trentenari para leer ante ellos diverses formes e maneres servades en las entrades dels reis passats $^{61}$. Tras la lectura de dichas ceremonias, entre las cuales sabemos que

${ }^{56} \mathrm{La}$ elaboración de un registro ceremonial continuado en el que quedase constancia, entre otras cosas, de todas aquellas recepciones solemnes organizadas por la ciudad era una de las tareas que los consellers de Barcelona cesantes encomedaban invariablemente a sus sucesores en el cargo. Dichas recomendaciones aparecen recogidas en la serie Testament dels Consellers del AHCB.

${ }^{57} \ll$ Urban records helped to establish the medieval city as a quasi-sacred center of ceremony and political prestige, while documentary rituals and obligations reinforced urban social cohesion» (B. BEDOS-REZAK, Civic Liturgies and Urban Records, p. 45).

${ }^{58}$ «...lo senyor rey vuy beneventuradament regnant se sperave dins breus dies entrar en la present ciutat e fer lo jurament acustumat e pendre e acceptar la fidelitat de sos vassalls, segons és stilat e praticat, sobre la qual entrada han trobat ells, consellers, en lo archiu del racional de la dita ciutat, e encara se lig en la Sancta Scriptura que, quant los reys novellament entren, per mostrar plaer e alegria de lurs novelles entrades, an aquells deuen ésser fetes festes e sollempnitats per lurs vassalls» (AHCB, CC, Deliberacions, II-12, f. 43v. 1458, agosto, 8. Barcelona).

${ }^{59}$ En Lérida, ante la entrada de Juan II en 1458: «...attès que no's trobava pràtica ne forma en alguns libres de la Casa de la Paheria de la manera que s'era tenguda en la recepció de alguns reys passats ne del jurament prestat de o per la novella venguda o ingrés en la present ciutat, segons ja dessús és feta menció, e era necessari hi fos provehit per la indempnitat de la ciutat, ajustaren los prohòmens per a les dites coses assignats...» (AML, Cerimonial Antich, reg. 700, f. 47 r. 1458 , octubre, 26. Lérida).

${ }^{60}$ «...le premier travail des échevins est de consulter la mémoire municipale à fin de s'enquerir des cérémonies faites autrefois en de telles circonstances» (D. RIVAUD, Les entrées royales dans les "bonnes villes", p. 289).

${ }^{61} \mathrm{AHCB}, \mathrm{CC}$, Deliberacions, II-12, f. 56v. 1458, noviembre, 3. Barcelona. 
estaba la correspondiente a la entrada de Fernando I en $1412^{62}$, el notario había abandonado la sesión, mientras en el interior de la sala se procedía a deliberar sobre lo allí escuchado. Recuperada oficialmente la memoria, Barcelona estaba ahora en condiciones de decidir cómo acoger al nuevo monarca o, cuando menos, de oponerse legítimamente a todo aquéllo que pudiese introduhir pràtiques noves e dampnoses a la dita ciutat ${ }^{63}$.

\section{4. ¿NEGOCIACIÓN?}

Hasta ahora, la prudencia nos ha llevado a citar entre comillas la palabra "negociación" en todas y cada una de las ocasiones en que ésta ha aparecido en el texto. Prudencia y - se ha de reconocer- una cierta y razonable duda acerca de si la elección de dicho término era la adecuada para el tema aquí tratado ${ }^{64}$. De hecho, su utilización responde más a una sensación de conjunto que no a la constatación de una acción específica planteada bajo tal calificativo. El diálogo - otro de los términos que se adecuan a nuestro particular enfoque - que se establece entre monarca y ciudad con motivo de la celebración de una entrada real no es únicamente un privilegiado momento de contacto entre ambos, sino que tiene como objetivo resolver una situación potencialmente conflictiva a través de la coincidencia de criterios - cuando éstos resultan ser divergentes-y de la búsqueda de provecho mutuo. Para tal resolución, las fuerzas que entran en juego no parecen explicitar su vocación negociadora ni plasmarla de una manera ritual y protocolariamente definible ${ }^{65}$.

\footnotetext{
${ }^{62}$ Además de ser mencionada en el documento citado, existe también la constatación del pago a un escribano, en octubre de 1458 , por «I traslat en paper que ha fet de tota la solemnitat, messions e despeses fetes per la entrada del senyor rey en Fferrando, de la senyora reyna e de llur primogènit...» (AHCB, CC, Correu i menut, XX-1, f. 3r)

${ }^{63}$ AHCB, CC, Deliberacions, II-12, f. 84v. 1458, diciembre, 20. Barcelona.

${ }^{64}$ En cualquier caso, se trata de una reflexión que afecta, en general, al propio significado del concepto en el mundo medieval. Véanse, en este sentido, las contribuciones de Jean-Marie MoEGLIN, Heurs et malheurs de la négociation du Moyen Âge à l'époque moderne, pp. 5-26, y de Pierre MONNET, Villes, ligues, princes et royauté; négociations et négociateurs dans l'Empire tardo-médiéval, pp. 215-239, en $\mathbf{M}^{\mathrm{a}}$ Teresa FERRER; Jean-Marie MoEgLIN; Stéphane PEQUIGNOT; Manuel SÁNCHEZ (eds.), Negociar en la Edad Media / Négocier au Moyen Âge, Barcelona, 2005.

${ }^{65}$ Quizá en consonancia con una estrategia diplomatica habitual, según la cual, y en palabras de Jean-Marie MoEGLIN, Heurs et malheurs, p. 18, «le premier qui reconnaîtrait explicitement qu'il est prêt à négocier ("tu me donnes ceci et je te donne cela") est celui qui aurait perdu».
} 
Lo que tiene lugar -obviamente, nos estamos refiriendo en todo momento a Barcelona, aunque algunas de estas consideraciones puedan resultar aplicables al modelo de las joyeuses entrées europeas ${ }^{66}$ - es un encubierto proceso de tanteo de fuerzas en el cual, bajo la apariencia diplomática, se dirimen los intereses de unos y las aspiraciones de otros con motivo de la celebración de la entrada real ${ }^{67}$. Y dado que ésta siempre acaba efectuándose - ya sea con solemnidad o sin ella-, es mediante ese diálogo previo, mediante esa negociación nunca reconocida, que la ceremonia adquiere significado y particularidad, rasgos sociales y políticos que luego quizá podrían - pero ello no es seguro- ser interpretados o deducidos a partir de los gestos y matices del ritual.

Richard Trexler, a la hora de visualizar las ceremonias de recepción en la Florencia renacentista, recurre al concepto de "capitulación" ${ }^{68}$, mientras que Francesc Massip define la entrada del rey en la ciudad como la plasmación del "contrato social" existente entre ambos ${ }^{69}$. En el caso que nos ocupa, el componente jurídico no ha de entenderse únicamente en sentido figurado, dado que la entrada real en Barcelona se desarrollaba entre dos actos de juramento: el que efectuaba el rey en el inicio de la ceremonia, garantizando las libertades del municipio y prometiendo respetar los privilegios otorgados a la ciudad por los anteriores monarcas ${ }^{70}$, y el que llevaba a cabo la ciudad,

\footnotetext{
${ }^{66}$ Según aparecen descritas en $\mathrm{M}^{\mathrm{a}}$ Pilar Monteagudo Robledo, Fiesta y poder. Aportaciones historiográficas al estudio de las ceremonias políticas en su desarrollo histórico, "Pedralbes", 15 (1995), p. 184: «...las joyeuses entrées del Norte son expresión de la vida de una ciudad y de las obligaciones mutuas que rigen sus relaciones con el príncipe. Las relaciones de protector a protegido son asumidas como un cambio de servicios, como una reciprocidad de derechos y deberes, sin servilismos, propio del orgullo corporativo defensor de las libertades comunales que sólo reconoce al soberano si éste asume sus compromisos».

${ }^{67} \mathrm{El} 9$ de agosto de 1458, en sesión del Consell de Cent, el conseller cuarto, Ramon Mora, había expuesto, entre otras cosas, las ventajas que, para la ciudad, podía suponer la llegada de Juan II. Según el conseller, solemnizar el recibimiento del rey implicaba, por un lado, favorecer una más decidida actitud del monarca a la hora de «benefficiar la present ciutat», y por otro, darle motivos para detenerse en ella, lo cual «redundaria en gran util dels habitants en aquella e augmentació de les imposicions» (Manual de Novells Ardits, vol. II, p. 292).

${ }^{68}$ «Host met guest in the context of a "capitulation", a formal ceremony in which the visitor swore before notaries to respect the freedom of the city» (Richard C. TREXLER, Public life in Renaissance Florence, Ithaca-Londres, 1991, p. 309).

${ }^{69} \mathrm{~F}$. MASSIP, La monarquía en escena, p. 24.

${ }^{70} \mathrm{El}$ de Juan II, el 22 de noviembre de 1458, aparece recogido en Federico UDINA MARTORELl (dir.), Privilegios reales concedidos a la ciudad de Barcelona, CODOIN, XLIII, Barcelona, 1971, pp. 252-253: «...laudamus, approbamus et in omnibus confirmamus vobis dilectis et fidelibus nostris Petro Serra, Jaufrido Sirvent, Bernardo de Granollachs, Raymundo Mora et Antonio Coco, consiliaris anno presenti civitatis Barchinone, ac universitati civitatis
} 
una vez concluidos los actos de la entrada, reconociendo al monarca como señor y prestándole la fidelidad debida ${ }^{71}$. El primero era condición inexcusable para que la ciudad aceptara acoger solemnemente al soberano; el segundo -que, en realidad, se integraba dentro del más amplio juramento que los distintos estamentos del reino realizaban ante el nuevo rey - sellaba la relación que se acababa de establecer.

Por tanto, no era tan sólo una cuestión formal lo que se dilucidaba en los contactos que, en la preparación de la recepción, mantenían los regidores municipales y la corte real. Lo que estaba en juego, lo que ponía en escena dicha ceremonia en su totalidad, era el marco mínimo sobre el cual habría de desenvolverse la coexistencia del poder real y del poder urbano ${ }^{72}$. Garantizar que nada pudiera desvirtuar, enrarecer o marcar negativamente dicho encuentro exigía, en consecuencia, el "ensayo" de la ceremonia. Ensayo sobre el papel, es decir, negociación.

Un aspecto éste que, en el caso concreto de la entrada de Juan II en Barcelona, en 1458, aparece claramente dimensionado, puesto que lo que en esa ocasión se planteó fueron no una, sino dos entradas. El tiempo transcurrido entre el juramento como soberano en Zaragoza y la llegada del rey a Barcelona, prácticamente cuatro meses más tarde, dio pie a que, desde agosto hasta octubre de ese año, se deliberara acerca de un modelo de entrada austero y sin celebración alguna, como correspondía a un acto real muy próximo cronológicamente a la muerte del anterior monarca, mientras que, a partir de

predicte perpetuo omnes concessiones, gracias et confimationes factas universitati civitatis predicte per serenissimos dominos reges Martinum, proavunculum, et Alfonsum, fratrem, et predecesores nostros felicis recordationis...»

${ }^{71} \mathrm{El} 24$ de noviembre de 1458, el Consell de Cent deliberaba acerca de esta circunstancia: «...fou possat en lo dit Concell, per lo dit honorable mossèn Joffre Servent, com segons era manifest a tots, lo senyor rey, vuy beneventuradanent regnant, entrà en la present ciutat dimecres proppassat e jurà tot ço que per los altres reys antecesssors seus és stat jurat e jurar devia. E lo dit senyor rey, com sia de rehó, vol que li sia prestada per sos vassalls la faeltat que a novell rey se deu prestar...» (AHCB, CC, Deliberacions, II-12, f. 63r. 1458, noviembre, 24. Barcelona). Finalmente, el juramento a Juan II tendría lugar el 29 de noviembre en el interior del Palacio Real: «...lo senyor rey, sehent en un alt cadafal en lo cap de la gran sala reyal del palau major de Barchinona, li fonch prestat lo sagrament e homenatge acustumat...» (J.M. SANS, Dietari $o$ Llibre de Jornades, p. 107).

${ }^{72}$ Muestra de ello es que, en la entrada en Lérida, en octubre de 1458, Juan II se negó a realizar el juramento en la forma que la ciudad le proponía, por cuanto no seguía al pie de la letra el texto jurado por sus predecesores en el trono «...lo senyor rey fos supplicat faça lo jurament segons la forma donada o scrita de mà del honorable micer Berthomeu Mahull, incipiendo Dominus rex confirmat privilegia, libertates, etc., la qual forma de jurament no és açí inserta per quant lo dit senyor rey no volch jurar en aquella manera, sinó segons los il·lustríssims reys en Fferrando, pare, e n'Ânfonso, frare, llurs, havien jurat» (AML, Cerimonial Antich, reg. 700, f. 47r.). 
mediados de octubre, al considerarse que ambos acontecimientos aparecían ya suficientemente distanciados, todo giró en torno a un nuevo modelo de recepción, ahora dotado de aquellos componentes festivos que adornaban tradicionalmente el primer ingreso del rey en Barcelona.

El 3 de agosto de 1458, el Trentenari -reunido en la logeta del ort de la Casa de la Ciutat $^{73}$-, a proposición de los consellers y tras alguns rahonaments, aprobaba que la primera visita de Juan II a la ciudad como monarca fuera celebrada con solemnidad y fiesta, aunque nada de ello debía ser aún comunicado al rey ${ }^{74}$. Sin embargo, apenas una semana después, el 9 de agosto, el Consell de Cent decidía, per alguns motius en lo dit Consell deduhits, que la entrada de Juan II no debía ser acompañada de festejo alguno $^{75}$. Nos es imposible precisar la naturaleza de dichos "motivos" ni el porqué del secretismo respecto al monarca, nunca explicitados por la documentación municipal, aunque todo parece indicar que estaban relacionados con la prudencia ceremonial que aconsejaba el reciente fallecimiento de Alfonso IV $^{76}$. El 24 de ese mismo mes, Juan II, tras solicitar - como ya hemos visto anteriormente $-\mathrm{y}$ recibir relaciones detalladas de las ceremonias de entrada en Barcelona de sus predecesores, confirmaba a los consellers su deseo de entrar en la ciudad sin fiesta alguna, aduciendo que si las entradas de Martín I y de Fernando I habían contado con una recepción solemne se debía al hecho de que la distància del temps de les morts de lurs predecessors comportaven que s fesen les festes e solemnitats que $l s$ foren fetes, ço que no ha loch en lo cas present ${ }^{77}$. En su intento por precisar cómo había de ser dicha

${ }^{73}$ «El Trentenari vell, el dels segles XIV i XV, constava d'una sala per a les reunions, d'una capella oberta en el mur del fons, i d'un pòrtic o llotja que ocupava un dels costats del pati dels tarongers» (Agustí DURAN I SANPERE, Barcelona i la seva història, 3 vols., Barcelona, 1972, vol. I, p. 293). La costumbre de reunirse fuera de la sala del Trentenari en los meses más calurosos del año parece ser una constante en estos años. La posterior sesión del 9 de agosto de 1458 tendría lugar «dins lo verger qui és en la Casa de la Ciutat» (AHCB, CC, Deliberacions, II-12, f. 43r)

${ }^{74}$ Ibídem, f. 42v. 1458, agosto, 3. Barcelona.

${ }^{75}$ Ibídem, f. 44r.

${ }^{76}$ Esa es, como mínimo, la explicación que ofrecen las Rúbriques de Bruniquer, vol. 1, p. 240: «...fou deliberat que per la Entrada del Rey don Joan nos fes festa per que lo Rey no la volía, per haver poch que son germà el Rey Don Alfonço era mort...». La ceremonia solemne en Barcelona por el alma del fallecido monarca había tenido lugar el 28 de julio de 1458.

${ }^{77}$ AHCB, CC, Lletres reials originals, IX-3, carta 755. También en ACA, C, reg. 3406, f. 29v. 1458, agosto, 24. Zaragoza. 
recepción, la carta de Juan II dividía la ceremonia en dos partes claramente diferenciadas.

Por un lado, aquella más sobria y centrada en el monarca que éste deseaba que se escenificara tanto en su entrada como en la de la reina ${ }^{78}$ :

...solament que cascú, en la sua entrada e jornada entrant en la ciutat aquesta primera vegada, entre sota lo pali que serà apparellat e acompanyat, segons en casos semblants és acustumat, e que lo catafal de fusta sia fet en la plaça davant frares menors, apparellat en la forma deguda e acostumada, per fer e prestar lo jurament solennament. segons e per la forma e manera que nostres predecessors reys d'Aragó, de loable recordació, han acostumat fer en lo inici de llur regiment. E, axí mateix, siam reebuts ab la processió del clero, axí com és acostumat...

Por otro, todos aquellos elementos que, a través del protagonismo de la ciudad, concedían a la entrada su carácter más festivo y que, por respeto a la memoria del recien fallecido Alfonso IV, no parecían oportunos en esta ocasión:

...remogudes totes altres festes de vestir consellers, de entremesos, de balls, justes ne ministrés...

Una distinción que, al mismo tiempo, mostraba, una vez más, en qué medida la entrada real era el resultado de la fusión de, como mínimo, dos expresiones: la que surgía de la solemnización de la monarquía y la que aparecía intrínsecamente ligada a la propia identidad del municipio.

A partir del modelo propuesto por el monarca, la ciudad ofrecía, días después, un primer esbozo de la ceremonia ${ }^{79}$. La recepción tendría lugar en el Portal de Sant Antoni, a continuación el rey juraría los privilegios y

\footnotetext{
${ }^{78} \mathrm{La}$ ceremonia de entrada real se hacía extensible tanto a la figura de la reina como a la del primogénito al trono, quienes solían disponer -aunque no siempre sucedía así- de celebraciones independientes de la del rey. Así, Juan II y su esposa, la reina Juana, habían entrado por separado en Lérida, aunque todo ello en el mismo día (AML, Cerimonial Antich, reg. 700, f. 48r-v), mientras que en Barcelona la entrada de la reina tendría lugar un día más tarde que la del monarca, es decir, el 23 de noviembre de 1458: «Lo dit die la senyora Reyna dona Johana muller del dit senyor Rey, vers mig jorn partint del dit Monastir de Valldonzella per lo dessus dit cami intra en Barchinona e munta al dit cadafall e sitial, hon vingueren los officis e confraries ab los entrameses e balls» (Manual de Novells Ardits, vol. II, p. 294).

${ }^{79}$ Aunque no se ha conservado dicha carta, sabemos, gracias a la respuesta posterior del monarca, que fue escrita el 7 de septiembre de 1458: «...vostra letra de VII del present mes de setembre havem rebuda, responsiva a altra nostra que us havíem tramesa sobre lo fet de la recepció nostra primera en aquexa ciutat...» (AHCB, CC, Lletres reials originals, IX-3, carta 759. También en ACA, C, reg. 3407, f. 8r. 1458, septiembre, 19. Zaragoza).
} 
libertades de Barcelona en la iglesia contigua de Sant Antoni y, desde allí mismo, bajo palio y a pie, sería acompañado por la procesión del clero barcelonés hasta la catedral. Un planteamiento quizá tomado de la recepción que tuvo lugar en 1416 con Alfonso IV y que, como es obvio, contrastaba enormemente con el desarrollo de una entrada real, convertida en esta ocasión en un mero acto protocolario dominado por el componente religioso.

Por la respuesta que Juan II, el 19 de septiembre, transmitía al Gobernador General de Cataluña, Galceran de Requesens ${ }^{80}$ - quién también parecía haber tomado parte en el debate junto a los consellers - la propuesta, aún siendo válida en lo que se refería al inicio de la ceremonia ${ }^{81}$, resultaba inaceptable en cuanto a su continuación: És veritat que venir la prosessó fins allí, e anar ab aquella, a peu, tro la Seu, appar a nós sia molt gran tret, e no decent ne pertinent que tant dega exir la prosessó. Por el contrario, lo que el monarca sugería era ir bajo palio, y a caballo, hasta la catedral, para allí ser recibido -como era habitual, por otro lado, en las entradas reales en Barcelona- por el clero ${ }^{82}$. En relación al itinerario a seguir desde el portal de Sant Antoni hasta la catedral, lo dejaba todo a juicio de la ciudad ${ }^{83}$.

${ }^{80}$ Miembro de la nobleza y Lugarteniente General de Cataluña entre 1453 y 1454, en lo que fue un nombramiento insólito hasta la fecha, puesto que se trataba de un cargo aparentemente reservado a los componentes de la familia real, Galceran de Requesens había sido la mano ejecutora mediante la cual Alfonso IV había intervenido contundentemente en el funcionamiento del Consell de Cent, redibujando su composición en favor de los sectores representados por el partido de la Busca, en detrimento del dominio histórico del grupo oligárquico de la Biga. Acerca de este asunto y de la trayectoria política de Galceran de Requesens entre 1453 y 1458, véase C. BATLLE, La crisis social y económica, vol I, pp. 260-270, 325-326 y 338-342.

${ }^{81}$ «...apar a nós bona la deliberació aquí aguda, ço és, que siam rebuts al portal de Sent Anthoni ab pali, e façam lo jurament acostumat dins la sglésia de Sent Anthoni» (ACA, C, reg. 3407, f. 7v. 1458, septiembre, 19. Zaragoza).

${ }^{82}$ «...ans serà millor que nós deguéssem anar a cavall, ab lo pali, fins a la dita Seu, e que nós descavalquem a la plaça Nova, e la creu que nós devem adorar a prop aparellada en la forma acostumada stiga davant lo portal de les Vèrgens, e de aquí avant entrem ab la prosessó en la Seu» (Ibídem).

${ }^{83}$ Juan II conocía bien las posibles variantes de dicho itinerario a través de la ciudad, tanto el trazado extenso que, pasando junto al templo de Santa María del Mar y la plaza del Born, estaba reservado a los miembros de la familia real, y que el ahora monarca había recorrido anteriormente en su entrada como Lugarteniente General en 1454 (véase fig. 2), como la versión reducida, a través del portal de la Boqueria y la plaza de Sant Jaume, que había utilizado en otras visitas no solemnes (la última, sin ir más lejos, en marzo de 1458) y que volvería a utilizar en el futuro (como, por ejemplo -véase fig. 4-, en diciembre de 1459, en el que fue su regreso a Barcelona tras la entrada real de noviembre de 1458). 
Los asuntos que retuvieron a Juan II en Zaragoza hasta finales de octubre $^{84}$-de los cuales lo único que conocemos con certeza es la enfermedad que pareció afectar a la familia real y a determinados servidores y miembros de la corte ${ }^{85}$ - parecieron relegar momentáneamente la planificación de la entrada a un segundo plano, hasta que, el 19 de ese mes, a través de una carta real en la que se respondía a una solicitud previa de los consellers de Barcelona, el monarca confirmó su predisposición, ahora sí, a ser recibido con la fiesta y solemnidad tradicionales de una entrada real ${ }^{86}$. Considerando que el tiempo pasado respecto a la muerte de Alfonso IV ya no interfería en el desarrollo de la ceremonia, Juan II manifestaba su complacencia ante la intención de la ciudad de festejar su entrada, y dejaba en manos de los consellers su realización per lo modo e forma que us plaurà e vist vos serà a vostra coneguda e arbitre.

La carta del rey, y el nuevo modelo de entrada que se planteaba en ella, activó una vez más la dinámica municipal al respecto. El 24 de octubre, los consellers escribieron a Juan II para obtener una confirmación definitiva de su próxima llegada a Barcelona ${ }^{87}$, y una semana después, el 31 de octubre, el Consell de Cent, tras ser leída ab alta veu la carta del 19 de octubre en la cual el monarca comunicaba su nueva opinión sobre la ceremonia de entrada, votó a favor de dicha iniciativa y autorizó a los consellers y al Trentenari a

${ }^{84} \mathrm{El} 25$ de octubre, los paers de Lérida eran informados de que «lo senyor rey ere ja partit de Çaragoça e fahie sa via per venir en la present ciutat» (AML, Cerimonial Antich, reg. 700, $\mathrm{f}$. 46v. 1458, octubre, 25. Lérida).

${ }^{85} \mathrm{El} 3$ de septiembre, en carta a la reina María, viuda de Alfonso IV, el monarca ya había mencionado la indisposición de una de las infantas (ACA, C, reg. 3406, f. 37v. 1458, septiembre, 3. Zaragoza). Un mes y medio más tarde, el 19 de octubre, dirigiéndose tanto a los paers de Lérida como a los consellers de Barcelona, Juan II atribuía el retraso en su visita a dichas ciudades a «molts e arduus affers que han occorregut e ab algunes indisposicions sobrevengudes a la dita reyna e als infant e infante, nostres cars fills» (ACA, C, reg. 3407, f. 18r-v. 1458, octubre, 19. Zaragoza). Igualmente, sabemos del pago a un especiero de Zaragoza, el 14 de octubre, «por razón de certas medicinas que, en días pasados, de su botiga hovimos tomado para nuestro servicio e de las gentes de nostra casa (...) para el dicho senyor rey e la senyora reyna, como para los infantes e fijos del dicho senyor rey, e diversas doncellas de la dicha senyora e de otras singulares personas de la casa de los dichos senyores que fueron neccesarias a sus malantias por ordinación de los metges» (ACA, C, reg. 3417, f. 48r. 1458, octubre, 14. Zaragoza).

${ }^{86} \mathrm{AHCB}, \mathrm{CC}$, Lletres reials originals, IX-3, carta 762. También en ACA, C, reg. 3407, f. $18 \mathrm{v} .1458$, octubre, 19. Zaragoza.

${ }^{87}$ «...e sia cosa que molt desigem saber la veritat, la qual no podem saber tant certa com per vostra excel·lència, per ço, ab aquella més affecció que podem, supplicam humilment vostra gran altesa li plàcia de la dita venguda nos scriure certament...» (AHCB, CC, Lletres closes, VI-21, f. 10v. 1458, octubre, 24. Barcelona). 
tomar las decisiones oportunas sobre dicha celebración ${ }^{88}$. Ese mismo día se hizo partícipe a Juan II de lo decidido por el Consell, al tiempo que los consellers, junto al Trentenari, asumían - y así lo notificaban al soberanola responsabilidad directa sobre los preparativos y la organización de la recepción ${ }^{89}$. La primera decisión al respecto se tomó ya en la misma carta, al solicitar al monarca que contemplase la posibilidad de retrasar la fecha de su entrada en la ciudad, a ffi que hajam temps de dar compliment en ço que mester sia ${ }^{90}$.

A inicios de noviembre, el mes en el que había de tener lugar la entrada real de Juan II en Barcelona, el Trentenari, tras escuchar de boca de Joan Oliver, notario del Racional, diferentes descripciones de ceremonias de entrada real en la ciudad - tal y como ya hemos tenido ocasión de comentarresolvió que la nueva recepción fuera hecha siguiendo el patrón de la realizada con ocasión de la entrada real de Fernando I en $1412^{91}$. Por su parte, el monarca, ya desde Balaguer, apremiaba a los consellers para que todo estuviese dispuesto a su llegada, prevista para el día 20 de dicho mes ${ }^{92}$. Sin embargo, la ciudad, que desde que había deliberado tomar la entrada de Fernando I como modelo a seguir, se hallaba embarcada en una frenética

${ }^{88}$ «E proposat lo dessús dit fet e lesta e entesa la letra dessús dita del molt excel·lent nostron rey e senyor, e votat per quescú del dit Concell, fou delliberat e conclòs per aquell que, per la primera beneventurada venguda que lo dit nostron rey e senyor, Déu volent, deu fer prest en aquesta ciutat, sia feta festa en la manera, forma e coneguda que serà delliberat per los honorables consellers presents e esdevenidors e per les XXXII ${ }^{\mathrm{es}}$ persones que ara són del Consell de XXXII» (AHCB, CC, Deliberacions, II-12, f. 56r. 1458, octubre, 31. Barcelona).

${ }^{89}$ «...lo qual Concell, per servei de vostra magestat e per gran contentació e alegria de vostra beneventurada venguda, ha delliberat que per aquella sia feta festa, la forma e manera com ha remesa a nosaltres, consellers e Concell de XXXII. Havem sperança, senyor, se farà en tal modo que serà a lahor de nostre Senyor Déu e a servei de vostra magestat...» (AHCB, CC, Lletres closes, VI-21, f. 12r. 1458, octubre, 31. Barcelona).

${ }^{90}$ En parecida forma se dirigían los consellers al Gobernador General de Cataluña, quien actuaría en todo este tiempo como intermediario entre el monarca y las autoridades municipales de Barcelona (Ibídem, f. 12v). Igualmente, los consellers escribían, también ese mismo día, al secretario real, Domingo Decho, rogando su intervención a fin de acelerar lo máximo posible la respuesta del rey (Ibídem, f. 13r).

${ }^{91} « \mathrm{E}$, a la fi, fou conclòs e delliberat que la dita festa sia feta segons forma de aquella qui fou feta al dit rey don Fferrando, e que lo donatiu del argent fahedor per aquesta ciutat al senyor rey e a la senyora reyna sia fet tal qual fou fet al dit rey don Fferrando e muller sua poch més o menys...»(AHCB, CC, Deliberacions, II-12, f. 56v. 1458, noviembre, 3. Barcelona).

92 «...nós som arribats en aquesta ciutat de Balaguer, de la qual, Déu volent, entenem demà partir ab propòsit de ésser aquí a la jornada del XX del present per nós assignada als convocats per nostres letres, car, attès la concurrència dels afers que tenim entre mans, (...) us pregam e encarregam, tant com podem, que doneu orde que totes les coses sien prestes e en punt per a la dita jornada...» (AHCB, CC, Lletres reials originals, IX-3, carta 767. 1458, noviembre, 10, Balaguer). 
búsqueda de telas, caballos y otros aditamentos lo más similares posible a los utilizados en aquella oportunidad, volvería a requerir de Juan II un ligero aplazamiento en la fecha de su entrada ${ }^{93}$. La petición, además de responder a supuestas exigencias verdaderas, formaba parte de un ritual de posible influencia romana ${ }^{94}$, por el cual se invitaba al monarca que hacía su primera visita a la ciudad a descansar uno o varios días a las puertas de la urbe, en el monasterio de Valldonzella ${ }^{95}$.

La carta enviada por los consellers al Gobernador General en esa misma fecha volvía a insistir en ello ${ }^{96}$, aprovechando al mismo tiempo para plantear un último problema de protocolo: se rogaba a Galceran de Requesens que se informase acerca del lugar que había de ocupar el infante Fernando en el catafalco desde el cual su padre iba a efectuar el solemne juramento a la ciudad, dado que no se había encontrado referencia alguna en el archivo municipal $^{97}$. Con ciertos reparos, la demora sería aceptada — desde Molins de

\footnotetext{
${ }^{93}$ «Per tant que totes les coses necessàrias a la festa e sollempnitat fahedora per aquesta ciutat per la felicíssima e novella entrada de vostra reyal persona e de la molt alta e molt excel·lent senyora, la senyora reyna, muller de vostra gran excel-lència, sien millor prestes e apparellades segons se pertany, havem delliberat supplicar vostra gran excel·lència li plàçia allonguar algun tant lo temps de la dita beneventurada entrada (...) almenys fins a dimecres primer vinent, que s compterà XXII del corrent mes...» (AHCB, CC, Lletres closes, VI-21, f. 21r. 1458, noviembre, 18. Barcelona).
}

${ }^{94}$ En la Roma antigua, la entrada solemne de los generales que regresaban victoriosos a la ciudad había de estar obligatoriamente precedida por un proceso simbólico de depuración de la sangre vertida durante el combate. Para este tema, véase H.S. VERSNEL, Triumphus. An Inquiry Into the Origin, Development and Meaning of the Roman Triumph, Leiden, 1970.

${ }^{95}$ Fundado en el siglo XIII bajo los auspicios de Jaime I, el recinto de este monasterio femenino de la orden del Císter había servido, y continuaría haciéndolo en los siglos siguientes, como lugar de descanso -real y figurado- de los reyes de la Corona de Aragón, básicamente cuando éstos llegaban desde Zaragoza, antes de entrar por primera vez en Barcelona. En realidad, formaba parte del propio ceremonial de la entrada real, por cuanto la acogida y recepción que el monasterio de Valldonzella concedía al monarca quedaba situada entre el inicial recibimiento institucional que el municipio hacía al soberano, a una cierta distancia de la ciudad, y la posterior entrada de éste en el interior de sus murallas. Para todo lo referente a la historia de este monasterio, véase Antoni PAUlí MelÉndeZ, Santa Maria de Valldonzella, Barcelona, 1972.

${ }^{96}$ «...nosaltres scrivim al senyor rey supplicant-lo sia mercè sua voler differir la sua felicíssima entrada en aquesta ciutat fins a dimecres primer vinent, e lo die abans sa magestat porà venir al monastir de Valldonzella a dormir, e l'endemà dimecres, de matí, Déu volent, entrar en la dita ciutat...» (AHCB, CC, Lletres closes, VI-21, f. 21v. 1458, noviembre, 18. Barcelona).

${ }^{97} \mathrm{La}$ solicitud reflejaba la situación anómala derivada del conflicto entre Juan II y su primer hijo, el príncipe de Viana, fruto del anterior matrimonio del rey con Blanca de Navarra. Enfrentados desde 1450, el monarca nunca había reconocido oficialmente a éste como primogénito al trono de la Corona de Aragón, en su intento por promocionar la figura del infante Fernando, futuro Fernando II de Aragón. Los consellers de Barcelona se veían, por tanto, obligados a procurar que ningún gesto del ceremonial pudiese interpretarse equivocadamente en este sentido. La postura de la ciudad en dicho conflicto quedaría de manifiesto en 1460, cuando el Príncipe de Viana, en su regreso a la Península, fue recibido en Barcelona con la solemnidad 
Rei, etapa habitual de los monarcas antes de llegar a Barcelona- por Juan $\mathrm{II}^{98}$, quien, el 22 de noviembre, mucho tiempo después de haber expresado su inicial intención de hacerlo, entraba finalmente en la ciudad.

Hasta el último momento, el ceremonial estuvo sometido a la incerteza y las modificaciones. De hecho, por el motivo que fuera - ya se tratase de un error del escribano, de una equivocación en el ritual o de un cambio a última hora-, la ordenanza pública del 19 de noviembre por la cual se anunciaba a la población de la ciudad la entrada de Juan II $^{99}$ informaba acerca de un itinerario (que desde el portal de Sant Antoni se dirigía, por las Ramblas, hasta la plaza de Framenors, lugar donde el monarca había de realizar el juramento de respeto a los privilegios y libertades del municipio, y donde, a continuación, había de desarrollarse el desfile festivo de oficios y entremeses de la ciudad) distinto del que finalmente realizó el monarca - quien accedió a la ciudad por el portal de les Drassanes (véase fig. 3)-, éste sí precisado por una nueva ordenanza del 20 de noviembre, en la que también quedaba de manifiesto el aplazamiento del día de la entrada hasta el miércoles 22 de noviembre (veáse doc. 2).

Todo ello, llámese negociación, diálogo o simplemente puesta en escena de un encuentro institucional, pone de manifiesto - tal como habíamos avanzado en la introducción de este trabajo- dos aspectos fundamentales. Por un lado, deja en evidencia que el ceremonial de la entrada real, mezcla de tradición y de adecuación a las circunstancias, capaz tanto de mimetizar el pasado como de innovar el presente, no responde a una imagen fija y repetitiva, desprovista de mayor significado que el de servir de rígido encaje formal a una celebración solemne. Por el contrario, lo muestra como algo maleable, cambiante, fragmentario, reunión de diversos elementos que aparecen y desaparecen, que cobran mayor o menor importancia, como resultado de la interrelación de las fuerzas que actúan sobre él. En ese sentido, y en segundo lugar, refleja perfectamente cómo el papel de la ciudad no se reduce ni al de mero escenario, ni al de protagonista secundario de una obra

correspondiente a un primogénito, ante la disconformidad del propio Juan II, en lo que sería uno de los claros preámbulos de la Guerra Civil que acabaría estallando en 1462.

${ }^{98}$ «...vostra letra havem reebuda e, vista, vos responem que serem contents sperar fins al dimecres vinent. Pregam, emperò, e encarregam-vos molt afectuosament per al dit dimecres la cosa no haga falla, car no ens poríem pus sperar...» (AHCB, CC, Lletres reials originals, IX-3, carta 769. 1458, noviembre, 19. Molins de Rei).

${ }^{99} \mathrm{AHCB}, \mathrm{CC}$, Ordinacions originals, XXXVI-8, carpeta 494. 1458, noviembre, 19. Barcelona. 
que tampoco, a pesar de las apariencias, está concebida únicamente para el rey.

\section{EPÍLOGO}

El 10 de enero de 1459, al anochecer, Juan II y la reina Juana abandonaban Barcelona en dirección a Valencia ${ }^{100}$. Aún así, las secuelas de la ceremonia de entrada de noviembre de 1458 se prolongarían durante meses. Hasta junio de 1459 , la ciudad no estaría en condiciones de formalizar la entrega al monarca de la vajilla de plata prometida en concepto de donativo por su entrada real ${ }^{101}$, en un diferido acto ceremonial que incluía tanto la exposición pública de sus piezas antes de ser enviadas a Valencia ${ }^{102}$, como el transporte de éstas y su adecuada presentación ante el soberano ${ }^{103}$. En ese mismo tiempo, el municipio había ido haciendo frente al goteo incesante de pagos pendientes que había dejado tras de sí la celebración de la llegada de Juan II $^{104}$, mientras la vida en el interior de las murallas parecía recuperar el pulso habitual tras la partida de la corte real.

${ }^{100}$ «Lo dit die en lo capvespre ab entorxes lo senyor Rey e la senyora Reyna partiren de la present Ciutat de Barchinona e anaren jaura a Molí de Reig per tirar camí vers la Ciutat de Valencia seguons fama» (Manual de Novells Ardits, vol. II, p. 298).

${ }^{101}$ En abril de 1459 , los consellers ya se habían dirigido a Juan II comunicándole los imprevistos que se habían producido en la elaboración de dicha vajilla (AHCB, CC, Lletres closes, VI-21, f. 53v), en lo que sería el inicio de un interminable intercambio de misivas entre la ciudad y el monarca en torno a esta cuestión, que no concluiría hasta la partida del donativo hacia Valencia, el 1 de junio de ese año: «Lo dit die lonorable en Johan Torrent ciutada elegit en portar e presentar lo argent del qual la present Ciutat fa donatiu al senyor Rey e senyora Reyna per llur novella entrada, parti de la present Ciutat ab lo dit argent» (Manual de Novells Ardits, vol. II, p. 306).

102 «...los honorables Consellers fferen fer o bastir I gran tinell en la sala o pati qui es al cap de la scala principal de la casa de la Ciutat, en lo qual, empaliat de drap de ras lenfront, ffou posada tota la vaxella dargent, la qual la dita Ciutat ha feta per lo donatiu que fa al senyor Rey e a la senyora Reyna per la llur novella entrada (...) E parat lo dit tinell stech axi parat tot lo dit die, fins a hora de completa, a comuna vista de qui veure ho volia...» (Ibídem, p. 306).

${ }^{103}$ Tenemos constancia de los trabajos de ornamentación encargados por la ciudad al pintor Jaume Vergós en relación a dicho envío: «...per senyals d'or e d'argent pintats sobre tela vermella qui són stats posats en les quatre caxas en les quals és stat mès e portat a València lo argent del qual la ciutat ha fet donatiu al senyor rey e a la senyora reyna per llur novella entrada...» (AHCB, $\mathrm{CC}$, Correu i menut, XX-1, f. 12v).

${ }^{104}$ Desgraciadamente, el registro de Clavaria correspondiente al período comprendido entre septiembre de 1458 y julio de 1459 no se ha conservado, aunque sí es posible encontrar en el siguiente volumen de esta serie referencias a algunos de dichos pagos (AHCB, CC, Clavaria, XI$72,1459-1460$ ). 
Sin embargo, a mediados de noviembre de 1459, una carta informaba a los consellers de la salida del rey de Zaragoza en dirección hacia Montblanc ${ }^{105} \mathrm{y}$, días después, éstos recibian el aviso oficial del monarca en que anunciaba su nueva visita a Barcelona. El ritual, como de costumbre, volvió a activarse, dentro de la dinámica protocolaria habitual de la ciudad. Tras conocer la intención del soberano de efectuar su entrada el día 3 de diciembre, los consellers reclamaron inmediatamente, a través de una carta dirigida al secretario del rey, saber el momento exacto del día en que ello sucedería para tener así dispuesto el pertinente recibimiento extramuros ${ }^{106}$. Finalmente, y partiendo desde Molins de Rei, Juan II y la reina Juana habían llegado, en el atardecer del día 4 de ese mes, a las inmediaciones de Barcelona, donde les esperaba la comitiva de recepción institucional de la ciudad. Luego, escoltados por los consellers, habían penetrado en el recinto amurallado y atravesado rápidamente la ciudad hasta su alojamiento en el Palacio Episcopal (ver. fig. 4) ${ }^{107}$.

Aún no se habían disuelto los ecos de la ceremonia de 1458 cuando ya se escenificaba un nuevo encuentro entre Barcelona y el soberano, ahora sin solemnidad alguna pero igualmente provisto de significado institucional. La entrada real, como es obvio, no detenía nada ni acaparaba las posibilidades expresivas del ceremonial urbano. Era, en todo caso -y con ello regresamos al inicio de este trabajo-, la expresión, quizá suprema, de una práctica incesante por la cual la ciudad, de la misma manera que se abría, podía también cerrarse.

\footnotetext{
105 «...de nit, ab llums d'entorxes, partí d'aquesta ciutat ensems ab la senyora reyna, e aquella nit se n' anà a Alfagarí (...) aprés, sens pasar per Lleyda, tirarà la via de Monblanch...» (AHCB, CC, Lletres comunes, X-29, f. 168. 1459, noviembre, 7. Zaragoza).

${ }^{106}$ «Del dit senyor havem letra ab la qual nos avise de sa entrada, que serà demà, que és dilluns, però ignoram si sa magestat entrerà per lo matí o al deprés dinar. Pregam-vos, per tant, quant pus affectuosament podem, sapiats ab lo dit senyor la hora que sa reyal persona entrar volrà, a fi que hajam temps de convidar aquells pròmens qui exiran ensemps ab nosaltres al dit senyor, al qual, com a feels affectats vassalls, desijam fer aquella més honor e subjeccció que possible nos és...» (AHCB, CC, Lletres closes, IV-21, f. 151v. 1459, diciembre, 2. Barcelona).

${ }^{107}$ Manual de Novells Ardits, vol. II, p. 325.
} 
Fig. 1 - PERIPLO SEGUIDO POR JUAN II DESDE SU ENTRONIZACIÓN ZARAGOZA EN 1458 HASTA SU LLEGADA A VALENCIA EN 1459

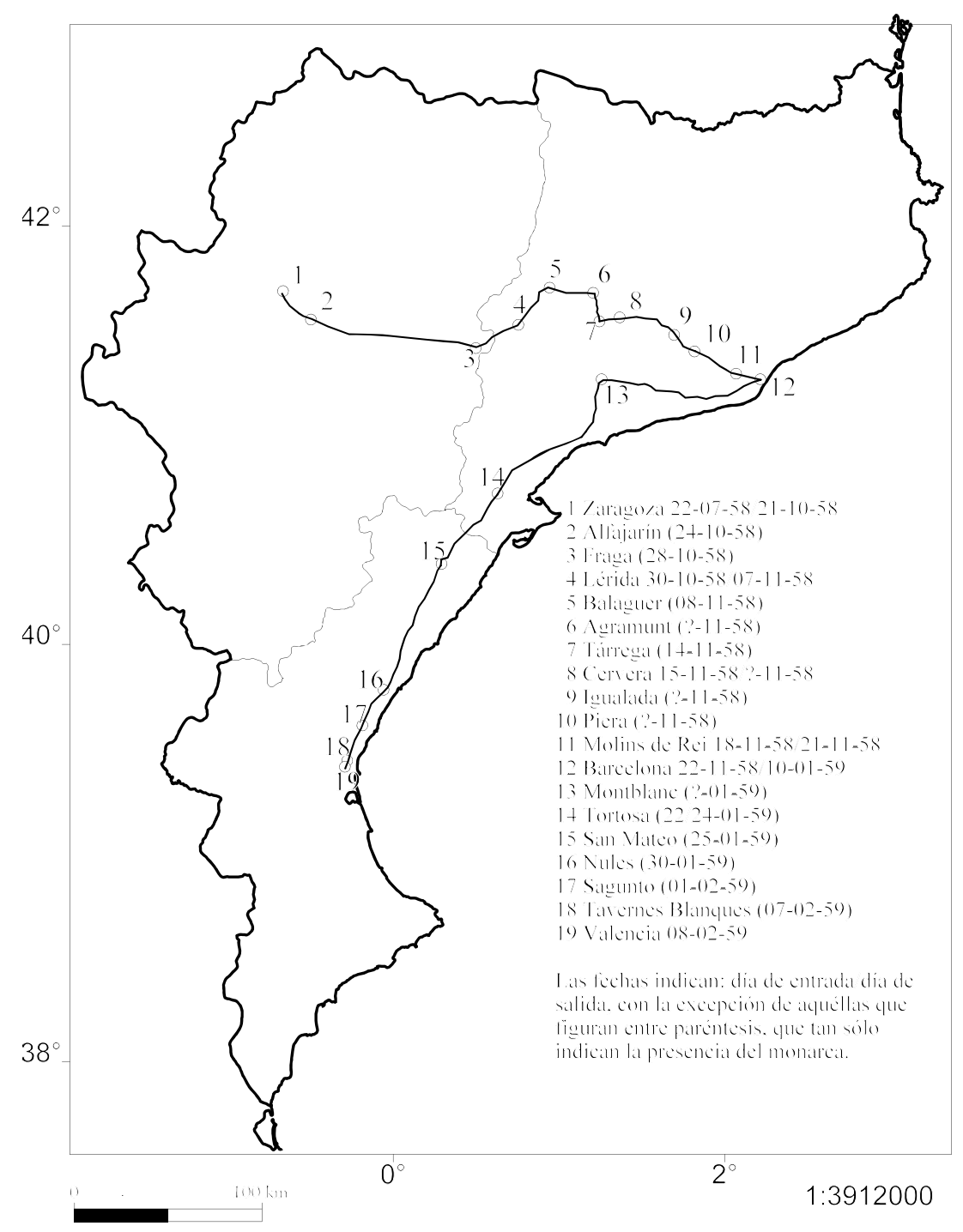




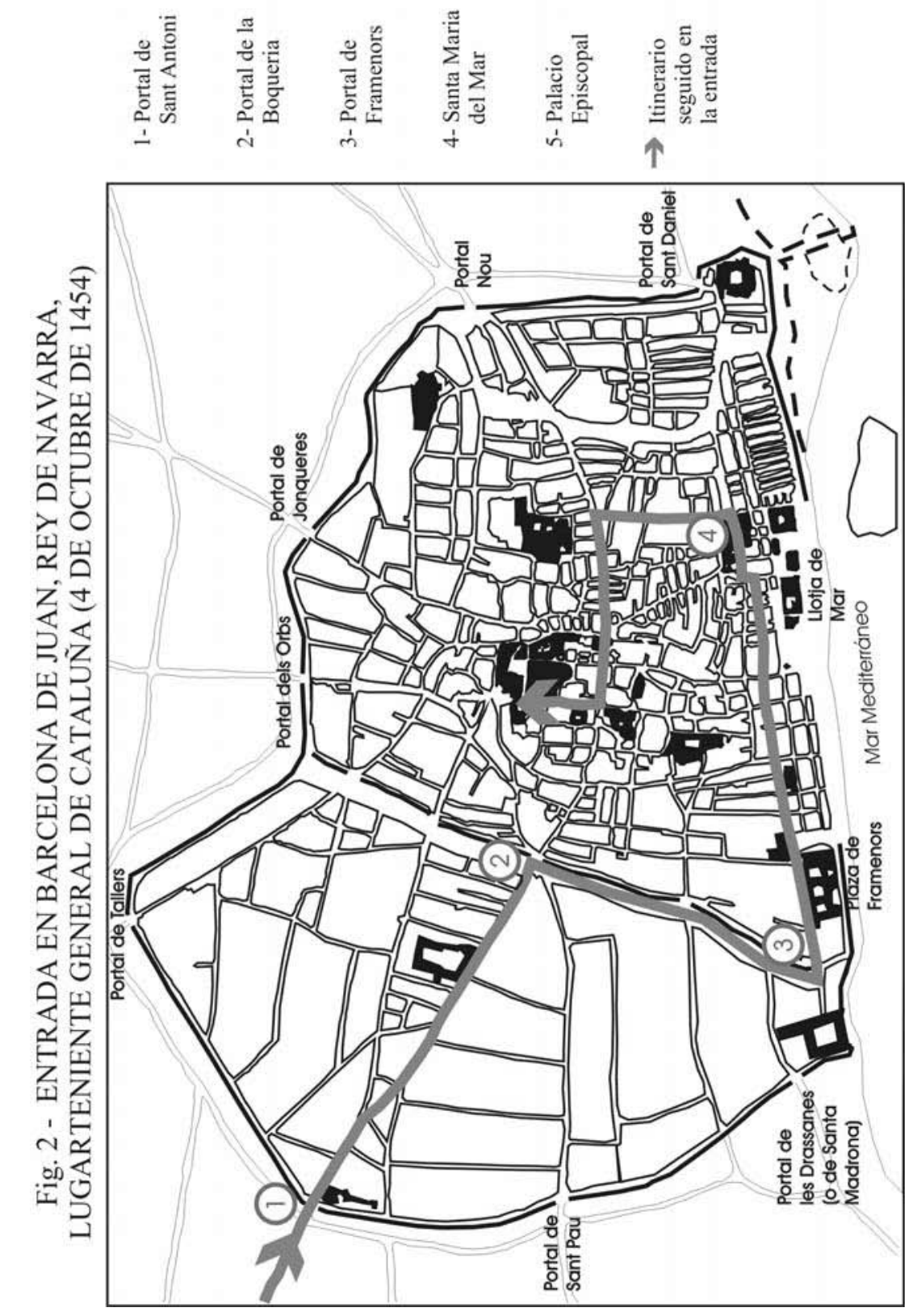




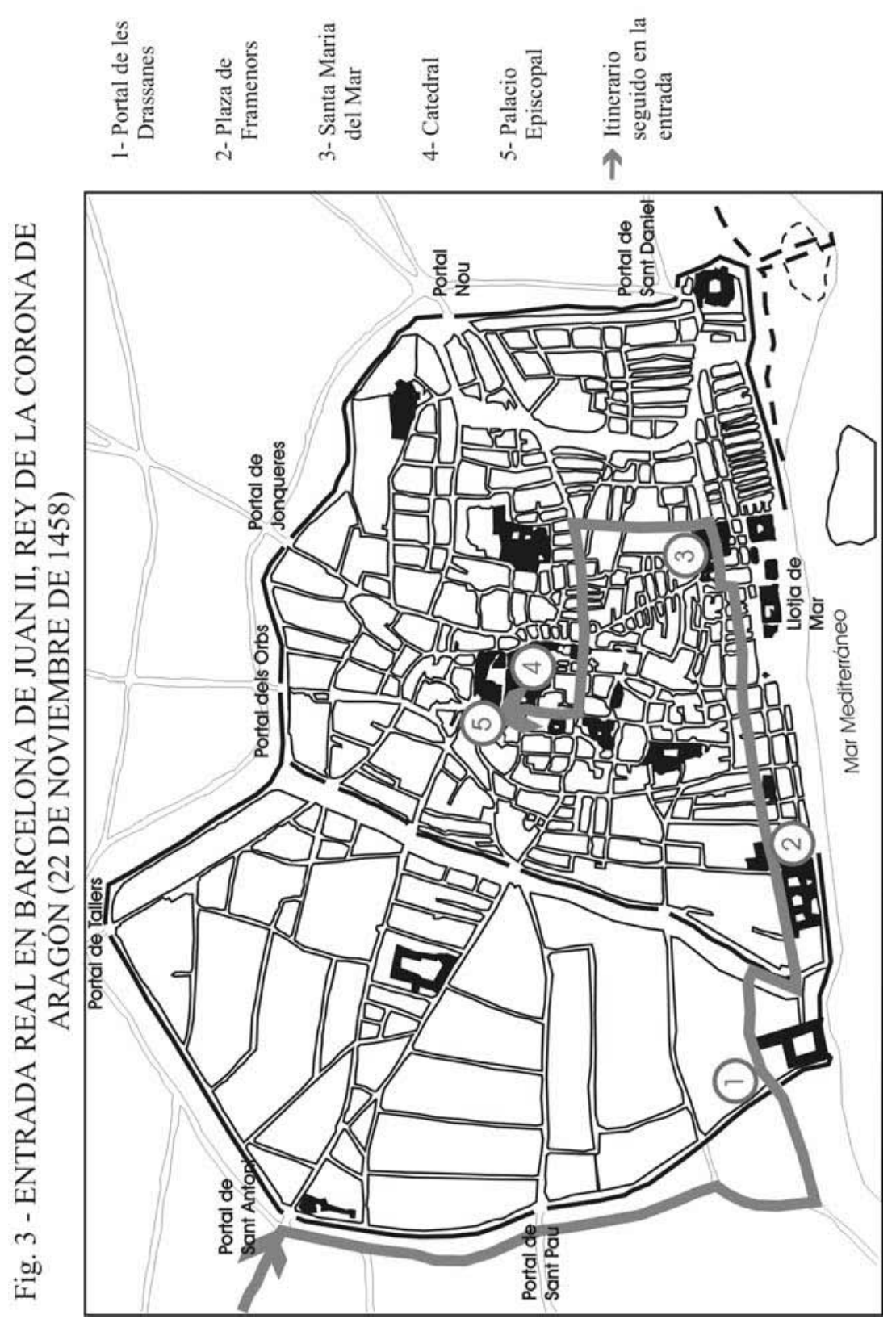




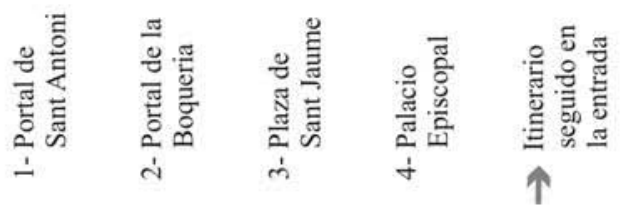

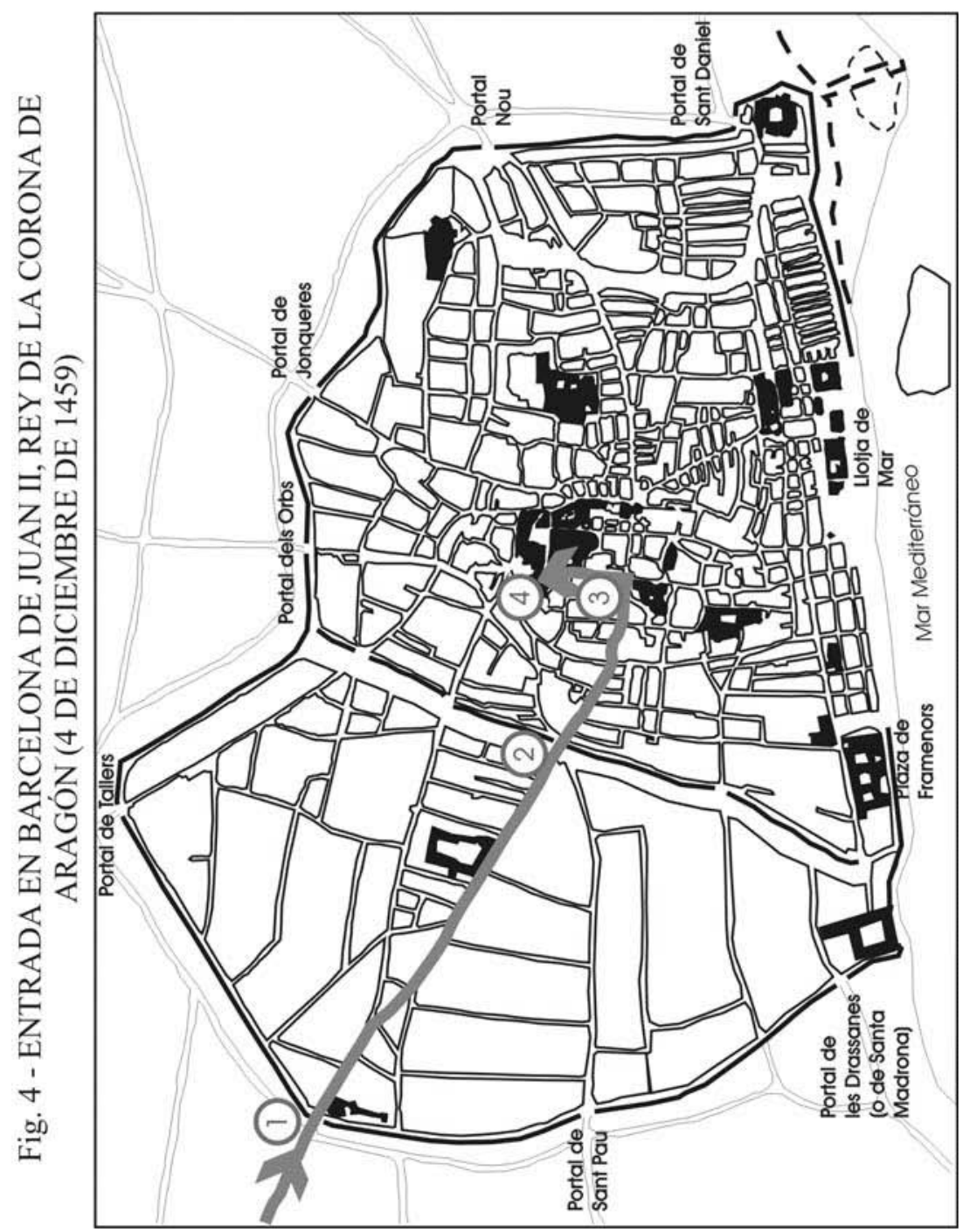




\section{APÉNDICE DOCUMENTAL}

1458, agosto, 19. Barcelona.

Los diputados del General de Cataluña responden a una carta anterior de Juan II, en la que éste les solicitaba un informe detallado acerca de las ceremonias de entrada de reyes predecesores suyos en Barcelona.

ACA, Generalitat, serie N, reg. 668, f. 70r-v.

Molt alt e molt excel-lent senyor:

Una letra de vostra gran excel-lència, feta a quinze del present, havem rebuda vuy, dada de la present, ja cerca lo migjorn, en la qual vostra excel·lència nos mane informem aquella de la recepció e festa qui fonch feta en aquesta ciutat als il-lustríssimos reys don Martí, venint de Sicília, e ab quina roba entrà vestit, e quina solemnitat li fou feta, e quants jorns durà la festa, e com anaven vestits lo dit rey e sos curials, axí hòmens com dones, en la festa e abans e aprés d'aquella, e per semblant de la recepció del senyor rey don Fferrando, pare, e del rey don Alfonso, frare, vestros de gloriosa memòria. E, encara, del rey don Johan. E quant temps passà de la mort del hu a l'entrada del altre, e com se regiren en portar lo dol los dits reys e les reynes, lurs mullers, e los de lurs cases.

Nosaltres, senyor molt excel·lent, vistes les coses dessús contengudes, per obeir a vostres manaments havem fet veure si trobaren en la casa de la Deputació tals actes o memorial de les dites coses, hon res no havem trobat qui per lo dit fet faça. Axí matex, ho havem fet demanar en l'archiu vostre, e tals coses ay tampoch $\mathrm{s} \cdot \mathrm{i}$ troben. Més avant, havem volgut sentir lo que se trobaria a la Casa de la Ciutat, hon se diu tals actes se acustumen metre en record, e no ho han volgut comunicar. Pensam, senyor, ho hajen fet per quant vostra senyoria los ha scrit. Crehem éls ne certifficaran largament vostra excel·lència.

$\mathrm{Ab}$ tot axò, senyor molt excel-lent, per retre nostre deute e obeir a vostra senyoria, havem ajustats dels pus ancians e notables cavallers e ciutadans de aquesta ciutat per certificar-nos de les dites coses, e per lur relació havem trobat que lo dit senyor rey don Johan, com lo senyor rey en Pere morí, era malalt a Hostalrich e, mort lo dit senyor en Pere, son pare, féu-se lo dit senyor rey en Johan portar en Barcelona ${ }^{a}$, e no's féu festa. En aprés lo senyor rey en Johan morí, e lo senyor rey en Martí ere en Sicília, hon havie feta la conquesta, e ans que vengués passaren bé dos anys; entrà 
en maig de $\mathrm{XC}^{\circ} \mathrm{VII}$, e fon-li feta gran festa. Lo senyor rey en Fferrando entrà en Barcelona a XXVIII de noembre del any mil quatra-cents e dotze, e fon-li feta gran festa, e lo sendemà fonch feta festa a la senyora reyna, sa muller, mare vostra, en la qual fon lo senyor rey don Alfonso, frare vestro. E lo dit senyor rey don Alfonso, aprés dos mesos, poch més o menys, de la mort del senyor rey don Fferrando, pare seu e vostre, entrà en Barcelona sens festa ab gramalla negre, e axí creu-se que, segons la distància dels temps e de les festes o no festes, los vestits de tots eren differenciats en lurs entrades.

E açò, senyor molt excel·lent, és lo que havem pogut trobar e no àls, attesa la antiquitat de les dites coses.

E man-nos vostra altesa lo que li sia plasent, la qual Nostro Senyor tinga en sa guarda e prosper votivament.

Scrita en Barcelona, a denou d'agost, en l'any de la nativitat de Nostro Senyor mil CCCC LVIII.

Senyor molt excel-lent, de vostra altesa humils súbdits e vassalls, qui a aquella humilment se recomanen, los diputats del General de Cathalunya residents en Barcelona.

$\mathrm{Al}$ molt alt e molt excel·lent senyor, lo senyor rey.

a. Barcelona, con abreviatura latina en el documento, y asi en adelante.

1458, noviembre, 20. Barcelona

Los consellers de Barcelona informan a los habitantes de la ciudad sobre las entradas de Juan II y de la reina, ahora aplazadas hasta los días 22 y 23 de noviembre, emplazándoles a manifestar su alegria ante dicho acontecimiento mediante la suspensión de toda actividad laboral, el uso de ropa adecuada, el embellecimiento de los lugares por donde discurrirá el itinerario de la entrada, y el encedido de alimares.

AHCB, CC, Ordinacions, IV-8, ff. 72v-73r.

Ara hojats tothom generalment que us notiffiquen los honorables consellers e pròmens de la present ciutat de Barcelona $^{a}$ que, dimecres primer vinent, que $\cdot s$ compterà XXII del corrent mes de noembre, lo molt alt e molt excel·lent senyor, lo senyor rey, entrerà en aquesta ciutat e, lo die aprés següent, entrerà la molt alta e molt excel-lent senyora, la senyora reyna, muller sua, per la qual novella beneventurada entrada és stat delliberat ésser feta bella festa e sollempnitat per la dita ciutat, segons se pertany. 
E entreran los dits senyor e senyora venint fora lo mur del Reval, entrant per lo portal de la Dresana e, dreta via, iran e pujaran sobre lo cadefal qui devant la plaça del monastir de Framenors és stat edifficat, e allí lo dit senyor rey, sollempnament, jurerà tot ço que per los alts reys de loable recordació, predecessors seus, és stat jurat. E del dit cadefal lo dit senyor mirarà molts e diverses entremesos, jochs e balls, los quals, per jocunditat e alegria de la sua felicíssima venguda e novella entrada, seran prests e apparellats, e denant li passaran. $\mathrm{E}$, aprés, lo dit senyor cavalcarà e irà per lo carrer Ample, tot dret, e, girant la via dels Cambis, passarà denant Sancta Maria de la Mar, fahent la volta del Born, e irà per lo carrer de Muntcada e, passant per la capella d'en Marchús, tirerà per la Bòria amunt, e per la plaça de les Cols, tot dret, a la plaça de Sanct Jacme, e d'aquí girerà la via de la Seu, hon lo dit senyor entrerà e, exint de la dita Seu, irà al Palau del Bisbe, en lo qual lo dit senyor se aturerà.

Per ço, los dits consellers e pròmens ordonen e preguen a tothom generalment que los dits dos dies vullen festivar e vestir-se quescú com millor porà, e los qui porteran dol durant les dites festes lo vullen posar. E, axí mateix, ordonen los dits consellers e pròmens que tots aquells qui stan o habiten en $\operatorname{los}^{b}$ carrers e vias dessús dits hajen agranar e empaliar los dits lochs per hon los dits senyor e senyora passaran. $\mathrm{E}$, més avant, ordonen e preguen los dits consellers e pròmens que, demà, que serà dimarts, a vespre, e l'endemà, dimecres, a vespres, tothom haje a ffer alimares per lurs cases, segons que en novelles entrades de reys e reynes és acustumat.

Ffou feta a XX de noembre de l'any M CCCC LVIII.

(En el margen superior, a modo de rúbrica) Per rehó de la entrada novella del senyor rey.

a. Barcelona, con abreviatura latina en el documento.- $b$. los interlineado. 